\title{
Numerical evidence against reversed thermohaline circulation in the warm Paleocene/Eocene ocean
}

\author{
Karen L. Bice \\ Department of Geology and Geophysics, Woods Hole Oceanographic Institution, Woods Hole, Massachusetts
}

\section{Jochem Marotzke}

School of Ocean and Earth Science, Southampton Oceanography Centre, University of Southampton, Southampton, England, United Kingdom

\begin{abstract}
The question of whether deep water formation might have occurred in subtropical latitudes in the early Cenozoic is examined through use of a global ocean model forced by mixed boundary conditions. Zonal mean surface temperatures and wind stresses are derived from an atmospheric general circulation model (AGCM) simulation of the warm Paleocene/Eocene boundary interval $(\sim 55 \mathrm{Ma})$ and are held constant for a series of sensitivity tests. The control case for moisture flux (evaporation minus precipitation, $E-P$ ), also derived from the AGCM, is perturbed so that the subtropical evaporation increases and high-latitude precipitation increases. A dramatic response is seen in the temperature and salinity structure of the model ocean, but the perturbation does not result in deep convection in subtropical latitudes. In all cases, bottom water is formed in the southern high latitudes, and the global meridional overturning is characterized by a strongly asymmetric circulation. No multiple equilibria have been found for any particular $E-P$ configuration. In the most extreme case ( 5 times the control $E-P$ ) the model oscillates between meridional overturning circulation "on" and "off." Shorter-lived thermohaline slowing and reinvigoration are observed as a transient response under less extreme $E$ - $P$ perturbations. Despite the high evaporation implied in the perturbation experiments, mean mixed layer salinities in the subtropics do not rise much above the control case because of efficient removal of salt (and heat) through deepened subduction beneath the subtropical gyres. The sensitivity of the results to the parameterization of continental runoff and the specified diapycnal mixing coefficient $\left(K_{v}\right)$ are also examined. Distributing runoff purely zonally, rather than globally, has approximately the same effect as a $50 \%$ increase in the strength of the hydrologic cycle. Decreasing $K_{v}$ to $0.3 \mathrm{~cm}^{2} \mathrm{~s}^{-1}$ from the standard value of $1.0 \mathrm{~cm}^{2} \mathrm{~s}^{-}$ ${ }^{1}$ increases the sensitivity to an increased hydrologic cycle considerably, but in no case does lowlatitude deep water formation occur, indicating that subtropical bottom water formation is implausible in a model with some degree of realism. These experiments support changes in moisture flux as a mechanism for ocean warming (largely in the thermocline through intermediate water depths), but the process involved is deepened subtropical subduction and not subtropical deep water formation.
\end{abstract}

\section{Introduction}

\subsection{The "WSBW" Hypothesis}

The potential for a significant subtropical bottom water source [Berger, 1979; Brass et al., 1982a, 1982b; Railsback et al., 1990] frequently referred to as "warm saline bottom water" (WSBW), during warm climate periods has been extensively debated since it was first suggested by Chamberlin [1906, p. 372]. Chamberlin proposed that dense, saline surface waters in the net evaporative latitudes "slowly descended and crept poleward, ... substantially maintaining their temperatures until they rose to the surface in polar regions and gave their warmth to the atmosphere." A meridional overturning system such as this would resemble Stommel's [1961] second case, in which salinity dominates the density difference between low and high latitudes and deep flow is from the

Copyright 2001 by the American Geophysical Union.

Paper number 2000JC000561.

0148-0227/01/2000JC000561\$09.00 "warm" to the "cold" region. Berger [1979] noted that during times of warm poles, salinity may have played a more important part in driving deep circulation. He questioned the feasibility of such a reversed circulation, however, noting that the most likely sources of dense saline water (large marginal seas) appear to have been brackish in most areas in the Cretaceous, except perhaps small regions of the Tethys Seaway (Figure 1).

In the past several decades, however, mid- to late Cretaceous ( 100-65 Ma) and early Cenozoic ( $65-49 \mathrm{Ma})$ geochemical, faunal, and sedimentological records have frequently been interpreted as reflecting changes in the relative importance of high-latitude deep water source(s) and an inferred subtropical warm, saline source, sometimes with abrupt climate change attributed to a sudden reversal of the meridional overturning circulation [Shackleton, 1982; Oberhänsli and Hsü, 1986; Prentice and Matthews, 1988; Kennett and Stott, 1990, 1991; Rea et al., 1990; Thomas, 1990; Mountain and Miller, 1992; Pak and Miller, 1992; Zachos et al., 1992; 1993; Kaiho et al., 1996; Thomas and Shackleton, 1996; Barrera et al., 1997]. This has occurred despite the fact that the true nature of the vertical structure of any early Cenozoic ocean is 


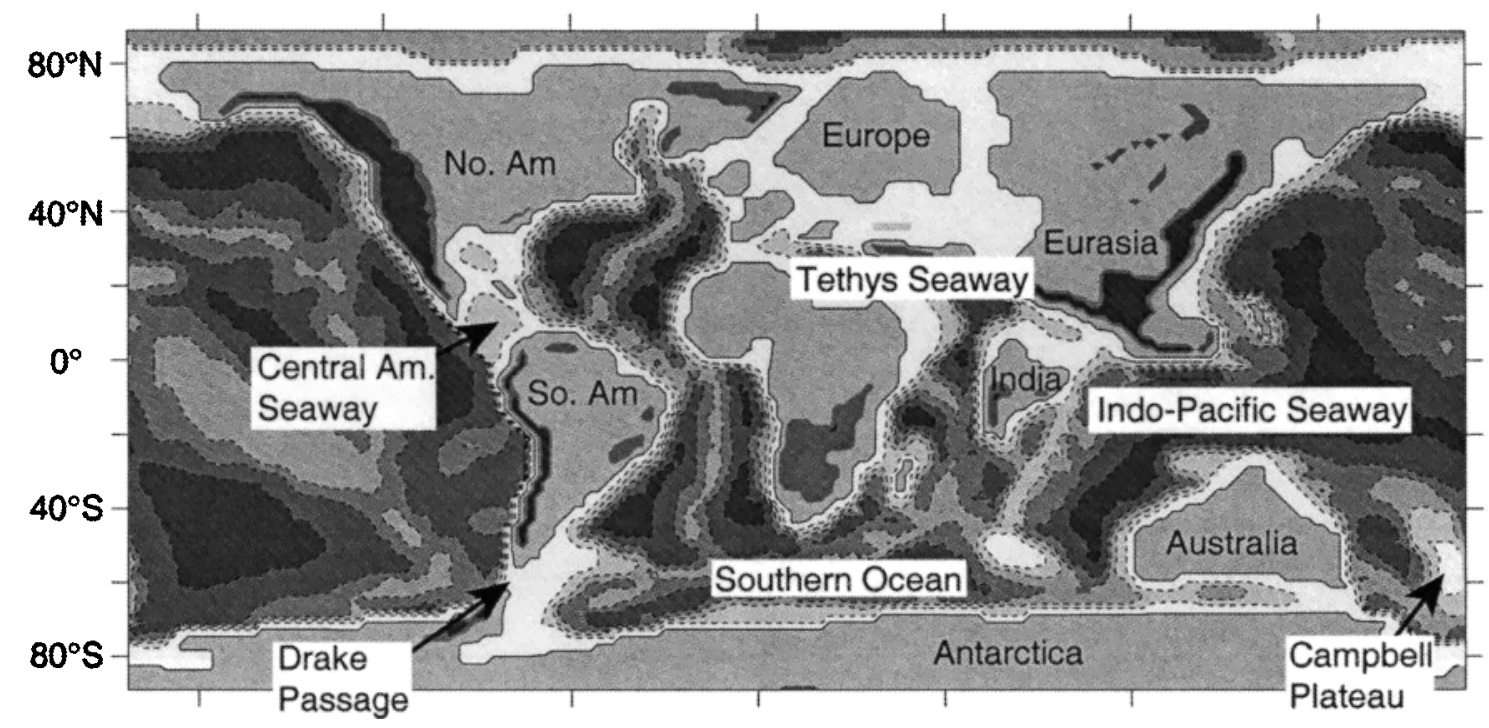

Figure 1. Reconstruction of the $55 \mathrm{Ma}$ geography at $2^{\circ}$ resolution. Solid curve indicates the shoreline. Dashed contours indicate ocean depths of $1,2,3,4$, and $5 \mathrm{~km}$.

poorly constrained and that no direct evidence exists to indicate formation of warm saline bottom water in a subtropical seaway [Pak and Miller, 1995; Crowley, 1999]. The geologic evidence cited by Brass et al. [1982b] as indicative of low-latitude bottom water formation is the benthic $\delta^{18} \mathrm{O}$ data that reflect bottom water cooling from $\sim 15^{\circ} \mathrm{C}$ in the Cretaceous to the modern values of $<2^{\circ} \mathrm{C}$. However, without consideration of the accompanying decrease in high-latitude upper ocean temperatures, the inference of a decreasing low-latitude bottom water source from the oxygen isotope trend is subject to debate.

Potentially, the most reliable indicator of relative bottom water age and proximity to source is the carbon isotopic composition of benthic foraminifera [Curry and Lohmann, 1982]. However, the utility of this proxy record is limited in many intervals because of removal of calcareous sediments through dissolution, uncertainties regarding the isotopic composition of end-member carbon sources, uncertainty in the fractionation of carbon by extinct benthic species, and data that may yet be too sparse to reliably reconstruct global deep water circulation patterns for the Cretaceous and early Cenozoic. Some limited benthic $\delta^{13} \mathrm{C}$ data has been interpreted as supportive of the existence of a subtropical bottom water source for a brief interval of time at or near the Paleocene/Eocene boundary, at $255.5 \mathrm{Ma}$ [Miller et al., 1987; Thomas, 1990; Thomas and Shackleton, 1996]. The region most often cited as the locus for potential WSBW formation is the Tethys Seaway (Figure 1). In the early Cenozoic the Tethys Seaway occupied $25 \%$ more surface area in the subtropical evaporative latitudes than exists in the Northern Hemisphere today.

The theoretical basis of WSBW rests in part on the supposed decreased potential for high-latitude convection given warm polar temperatures. Because seawater density decreases with increasing temperature, warm early Cenozoic high-latitude surface waters might have been less dense than those of the modern ocean, with deep convection there potentially less likely. The existence of an extensive seaway in the net evaporative subtropics might have allowed for the development of a substantial high-salinity low-latitude surface water mass. Owing to the nonlinearity of the equation of state of seawater, salinity influences on density generally are smaller in warmer climates and at low latitudes [e.g., Gill,
1982]. This adds to the difficulty of creating a salinity-dominated thermohaline circulation (THC). While the density contrast between high- and low-latitude surface waters may well have been reduced during intervals of extreme high-latitude warmth, it would have required a substantial change in salinities to reverse the meridional density gradient. New experiments described here attempt to impose such a contrast through substantial changes in moisture flux distribution.

\subsection{Previous Attempts to Simulate WSBW}

The hypothesis of WSBW received support from the numerical experiments of Brass et al. [1982a, 1982b] and Barron and Peterson [1990, 1991]. Brass et al. [1982a] described a simple steady state model for one or more turbulent plumes. A plume, driven by an imposed buoyancy source, would entrain ocean interior water, increase in volume transport and decrease in density as it sank. By assuming that the strength of a deep water source (the volume fiux times the density anomaly of the turbulent plume) governs its eventual depth and geographic distribution and that this buoyancy flux depends only on basin area and evaporation rate, Brass et al. hypothesized that times of large seas in net evaporative regions (e.g., the Cretaceous and early Cenozoic) were times during which the dominant global bottom water was warm as a result of having been formed in these regions.

In coarse-resolution ocean general circulation model experiments forced by output from the Community Climate Model, version 0 atmospheric general circulation model (AGCM), Barron and Peterson [1991] concluded that Eocene (40 Ma) paleogeography gave rise to deep convection in the subtropical northern Tethys Seaway, while modern geography and that reconstructed for $20 \mathrm{Ma}$ and $60 \mathrm{Ma}$ predicted only polar ocean deep convection. They achieved a similar result for a mid-Cretaceous (100 Ma) paleogeography when atmospheric $\mathrm{CO}_{2}$ was increased [Barron and Peterson, 1990]. However, the simulations of Barron and Peterson neglected continental runoff in deriving the salinity forcing for the model ocean, resulting in a net negative moisture balance over the global ocean.

Addressing this problem, Bice et al. [1997] showed that while 
convection might still occur in the early Eocene northern Tethys, depending on how continental runoff is distributed to the model ocean, the most realistic parameterization of runoff (using a crude reconstruction of Eocene drainage basins) results in deep water formation only in the high latitudes. When runoff is distributed evenly to all ocean model cells or is ignored in the calculation of moisture flux to the surface ocean, shallow midlatitude convection occurs; however, the flux of warm saline water is small, extends to depths shallower than $1500 \mathrm{~m}$, does not cause warming much beyond the Tethys basin, and does not result in the reversal of meridional overturning envisioned by Chamberlin [1906] and by Kennett and Stott [1990]. In fact, numerous early Eocene global model sensitivity tests using improved, higher-resolution atmosphere and ocean GCMs resulted in the prediction of only highlatitude deep water sources [Bice, 1997; Bice et al., 1998, 2000]. Bottom waters were warmer than modern waters because the high-latitude surface forcing temperatures were higher. Using the same ocean model, similar results were obtained by Brady et al. [1998] for the mid-Cretaceous, with bottom water produced in the Cretaceous southern high latitudes. Brady et al. distributed continental runoff evenly to all ocean model cells and observed a region of shallow convection that agrees with the Tethyan bottom water source region simulated by Barron and Peterson [1991], as did Bice et al. [1997] when not using a reconstruction of continental drainage basins. The correct explicit treatment of continental runoff is important in terms of its role in deep water formation, but it is a boundary condition about which there is a high degree of uncertainty for past intervals. Because of this importance, the question of whether WSBW was formed in the Tethys or another evaporative region during the Eocene or any other interval, or how it was formed, remains unanswered. While global numerical simulations performed to date do not support the WSBW hypothesis, the experiments of Bice et al. [1997] point to an increase in salınity in the Tethys Seaway as a plausible mechanism for initiation of or increase in the flux of a warm saline low-latitude intermediate to deep water mass, if one is likely to have occurred.

\subsection{Previous Thermohaline Circulation Modeling}

Beginning with the pioneering work of Bryan [1986] who demonstrated the existence of multiple equilibria of the thermohaline circulation under identical assumed atmospheric forcing, much modeling work has been devoted to THC dynamics in general (see review by Rahmstorf et al.[1996]). Manabe and Stouffer [1988] found two stable quasi-equilibria of the THC (and hence of climate) in a global coupled atmosphere-ocean model. Marotzke and Willebrand [1991] identified four stable equilibria in an idealized global THC model and argued that there were unlikely to be more, a picture that was largely confirmed by the more extensive investigation of Hughes and Weaver [1994].

Past investigations of THC sensitivity to external parameters that are particularly relevant to the present study have focused on the strength of the freshwater flux forcing, relative to thermal and wind forcing. In a single-hemisphere sector model with no wind forcing, Marotzke [1989, 1990] found a "collapsed" THC state that over 7000 model years displayed weak shallow low-latitude sinking and a warm, saline deep ocean. However, this was not an equilibrium solution. Eventually, extremely strong convection occurred at middle and high latitudes, a process later termed "flush" by Weaver and Sarachik [1991]. This led to extreme THC strength and cooling of the deep ocean to near high-latitude surface temperatures within $\sim 100$ years. This was followed by lowlatitude sinking again, and the collapse-flush cycle repeated itself.
With wind forcing present, Marotzke [1990] did not find the lowlatitude sinking (or "warm saline bottom water" state). However, under stronger freshwater flux forcing, Weaver and Sarachik [1991] obtained a similar collapse-flush cycle even in the presence of wind forcing and in a two-hemisphere sector model. Subsequently, Weaver et al. $[1991,1993]$ showed, again in a onehemisphere sector model, that increasing the freshwater forcing yielded, in turn, steady high-latitude sinking, unsteady high-latitude sinking, and the collapse-flush cycle (also termed "deepdecoupling oscillations" by Winton and Sarachik [1993]). Wang et al. [1999a, 1999b] used an idealized global model to investigate the sensitivity of the THC to changes in freshwater flux forcing. However, they analyzed only the strength and stability of the "conveyor belt" equilibrium (deep sinking in the North Atlantic but not in the North Pacific), and while they repeatedly found collapsed THC states, they did not investigate the issue further.

The crucial point that arises from these studies of THC stability is that in model runs dominated by salt forcing, a steady state solution with WSBW was never achieved. Low-latitude sinking as a steady solution occurred only with weak, pure haline forcing (no thermal or wind forcing) [Huang, 1994]. We emphasize that the nature of the unsteadiness was not a small variation about some mean but the complete reversal of the THC as exhibited during a "flush." Thus there is the following, nontrivial, zero-order question for paleoceanography: Is a WSBW steady state condition (a THC equilibrium without high-latitude sinking) dynamically possible at all, under realistic geometries, and if so, how is a flush prevented from occurring?

The purpose of the present paper is to reexamine the THC of a warm polar interval utilizing experience from THC studies outside paleoclimate applications. Our approach is intentionally a "constraining" one, where we attempt to force subtropical convection in the model. In a global model with realistic paleogeography and mixed boundary conditions we examine the sensitivity of the THC to changes in the distribution of moisture in the salinity forcing. Does application of a dramatically increased freshwater flux at high latitudes and decreased subtropical flux allow a "reversal" of meridional overtuming circulation? By selecting the boundary conditions appropriate for $\sim 55.5 \mathrm{Ma}$, an interval of some of the warmest high-latitude temperatures of the past 90 million years, we are maximizing the potential for WSBW formation in terms of temperature. We imply by this that if the moisture flux conditions required to produce subtropical sinking in the model are unrealistic, or if subtropical sinking does not occur given any moisture flux profile, then WSBW is not supported for the early Cenozoic and is also not supported for intervals of cooler polar temperatures with similar geographies.

\section{Model Description}

Atmospheric boundary conditions for ocean model experiments are taken from an AGCM simulation run using the Global Environmental and Ecological Simulation of Interactive Systems (GENESIS) version 2.0 model [Thompson and Pollard, 1997]. Topography consists of a $2^{\circ}$ resolution reconstruction of $55 \mathrm{Ma}$ paleogeography (Figure 1) [Bice et al., 1998]. The model atmospheric composition $\left(\mathrm{CO}_{2}=800 \mathrm{ppm} ; \mathrm{CH}_{4}=16.5 \mathrm{ppm}\right)$ and poleward heat parameterization ( 7 times the modern control value) were tuned to produce a qualitatively good match to published estimates of $\sim 55 \mathrm{Ma}$ sea surface temperatures: approximately $10^{\circ} \mathrm{C}$ at the poles and $32^{\circ} \mathrm{C}$ at the equator (Figure 2a). The simulated $22^{\circ} \mathrm{C}$ surface temperature gradient yields an $18^{\circ} \mathrm{C}$ surface temperature at paleolatitude $63^{\circ} \mathrm{S}$, a value within the uncertainty 

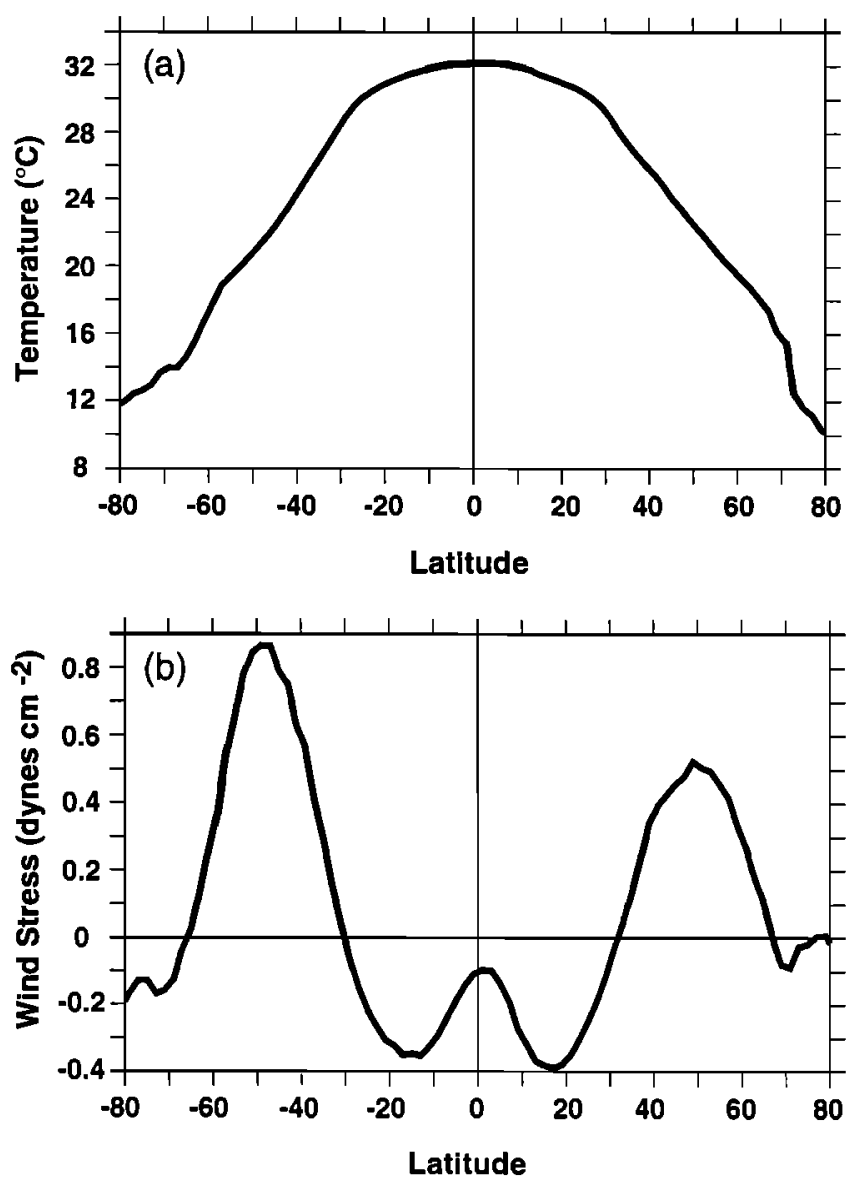

Figure 2. (a) Temperature $\left({ }^{\circ} \mathrm{C}\right.$ ) and (b) wind stress forcing (dyn $\mathrm{cm}^{-2}$ ) used in all experiments.

in the $20^{\circ} \mathrm{C}$ estimate for Maud Rise at $\sim 55.5 \mathrm{Ma}$ [Stott et al., 1990].

Surface air temperatures and eastward wind stresses at the surface were averaged zonally for the last 5 years of a 27 -year model run (Figure 2). To obtain a moisture flux forcing (Figure 3 ) to the ocean model, a more sophisticated treatment of AGCM output was required. First, evaporation minus precipitation $(E-P)$ rate (m $\mathrm{yr}^{-1}$ ) was calculated and then interpolated to $4^{\circ}$ horizontal resolution, with a small global correction applied as necessary to maintain a net zero global moisture flux. The resulting twodimensional $E-P$ field was then compared against the $4^{\circ}$ resolution land/sea mask prepared for the ocean model. Net precipitation (negative $E-P$ ) over the continents was summed and redistributed evenly to all ocean areas, and the resulting field was averaged zonally. This "global correction" represents an unrealistic treatment of continental runoff but assures a global moisture flux balance. The implications of this parameterization were considered by Bice et al. [1997] and are also examined in the present study.

The ocean model used is the Geophysical Fluid Dynamics Laboratory Modular Ocean Model version 2.2 (MOM2) [Pacanowski, 1996]. The model grid configuration has $4^{\circ}$ horizontal resolution everywhere, with 15 vertical layers, the first nine layers comprising the uppermost $1500 \mathrm{~m}$ of the model ocean. The uppermost layer is $25 \mathrm{~m}$ thick. The $55 \mathrm{Ma}$ paleobathymetric reconstruction of Bice et al. [1998] was modified to be consistent with the $2^{\circ}$ resolution continental reconstruction specified to the AGCM. The primary differences between this reconstruction and the modern ocean are a closed Drake Passage $(<100 \mathrm{~m}$ deep), closed Austra-
lia-Antarctic passage, a smaller Atlantic basin, and open (to various depths) low-latitude gateways (Indo-Pacific, India-Asia, eastern Mediterranean, and Central American passageways). The tectonic evolution of a high-latitude seaway(s) between South America and Antarctica is unsettled; however, there is no evidence to support a deep gateway as early as $55 \mathrm{Ma}$. The recent reconstruction by Lawver and Gahagan [1998] of a narrow, shallow passage in this region in the early Cenozoic forms the basis for our 100-m-deep "closed Drake."

All ocean runs are forced by "mixed thermohaline surface boundary conditions" [e.g., Bryan, 1986; Weaver and Sarachik, 1991; Marotzke and Willebrand, 1991] (also used by Barron and Peterson [1990, 1991] and Bice et al. [1997]). We assume that surface air temperature, surface winds, and the surface freshwater exchange are controlled by the atmosphere. $E-P$ calculated from the AGCM is specified to the model, where it is converted to a salt flux assuming a globally constant reference salinity of 35 practical salinity units (psu).

A simple relaxation condition for sea surface temperatures (Newtonian damping toward zonally averaged surface air temperature) is used as an approximation to the more complicated bulk formulae that use sea surface temperature, surface air temperature, wind speed, and static stability. A Newtonian damping timescale of 50 days is specified. Simple relaxation is appropriate in these experiments since we wish to address a first-order question: How strong a salinity forcing is needed, compared to thermal forcing, to induce WSBW? Variations stemming from zonal dependence of surface air temperature, or from spatial dependence of the relaxation timescale, will be explored in future work. In a similar vein, the assumption of annual mean conditions allows us to pose as simple a problem as possible. While the seasonal cycle is important in water mass formation, omitting it constitutes a quantitative, rather than a qualitative, simplification [Myers and Weaver, 1992]. In the ocean, water mass properties are set in late winter, when convection reaches deepest. Omitting the seasonal cycle from the thermal forcing, therefore, is best interpreted as a "perpetual late winter" scenario, rather than forcing with the annual mean. Given the uncertainties in the forcing of any paleocean model, we consider this idealization minor.

The acceleration technique of Bryan [1984] is used, with different time steps for temperature/salinity (1 day) and momentum/ vorticity (1 hour), but without the acceleration with depth.

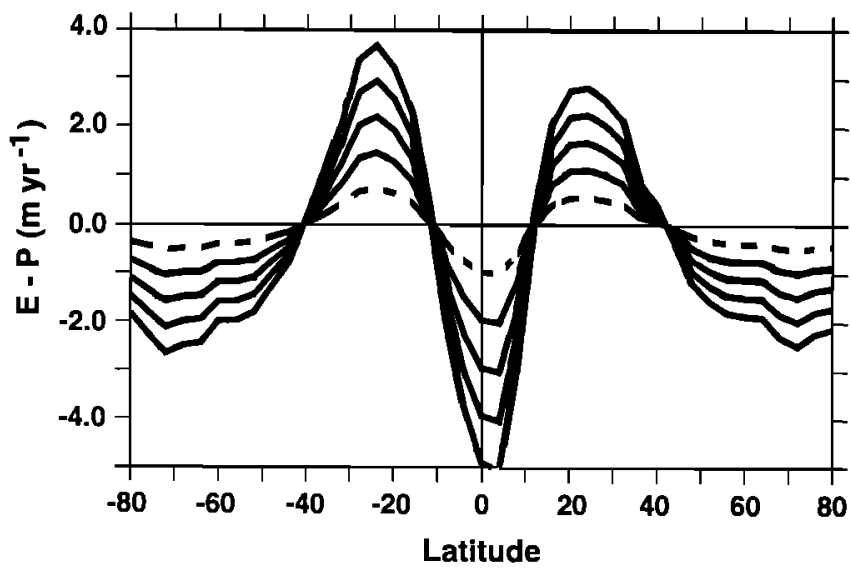

Figure 3. Evaporation minus precipitation $\left(\mathrm{m} \mathrm{yr}^{-1}\right)$ forcing used in experiments $1-5$. The control case (experiment 1 ) predicted by the AGCM is indicated by the dashed curve. Solid curves indicate the $2 \mathrm{x}, 3 \mathrm{x}, 4 \mathrm{x}$ and $5 \mathrm{x} E-P$ cases, with progressively decreasing tropical and high-latitude $E-P$. 
Whether the steady state results are sensitive to the integration technique is tested by appending to experiment 1 an integration period with equal time steps after an equilibrium had been reached [e.g., Marotzke, 1991]. The model solution does not diverge from the accelerated run during a 400-year integration with equal time steps (1 hour).

Because warm bottom water temperatures and abnormal salinities are expected given the warm polar forcing and the extreme $E$ - $P$ perturbation forcings, the coefficients used in the third-order polynomial approximation to the equation of state are interpolated between minimum and maximum $T$ and $S$ values that encompass the range of values expected in these experiments. Initially, the entire suite of experiments was run using $10^{\circ}-32^{\circ} \mathrm{C}$ and 28-39 psu as the limits for $T$ and $S$ in the MOM2 density coefficient routine. The results were seen to be insensitive to the range of values chosen by repeating four runs (experiments 2-5) with a wider range of values specified $\left(2^{\circ}-33^{\circ} \mathrm{C}\right.$ and $\left.0-43 \mathrm{psu}\right)$ as bounds for the polynomial fit.

The effects of mesoscale eddies are parameterized according to Gent and McWilliams [1990]. The along isopycnal diffusivity and isopycnal thickness diffusivity are set to $1.0 \times 10^{7} \mathrm{~cm}^{2} \mathrm{~s}^{-1}$, and the maximum isopycnal slope is 0.01 . The horizontal and vertical viscosity coefficients are $1.0 \times 10^{9} \mathrm{~cm}^{2} \mathrm{~s}^{-1}$ and $20.0 \mathrm{~cm}^{2} \mathrm{~s}^{-1}$, respectively. A constant vertical diffusivity coefficient of $1.0 \mathrm{~cm}^{2}$ $\mathrm{s}^{-1}$ is used. The sensitivity of the model to the specified diapycnal diffusivity is examined in an additional series of experiments in which $K_{v}$ equals 0.3 . The MOM2 "full convection" option is enabled, which completely removes static instabilities in the water column in one mixing pass at every time step [Rahmstorf, 1993]. Experiment 1 was initialized from a motionless state with uniform layer salinities from modem observations [Levitus, 1982] and uniform layer temperatures warmer than the modern, starting at $32^{\circ} \mathrm{C}$ in the uppermost layer and decreasing exponentially to $15^{\circ} \mathrm{C}$ at the bottom layer. The solutions were seen to be insensitive to the initial velocity and temperature structure by repeating experiments 1-5 initialized with modem layer average temperatures and a motionless state.

Some further comments regarding the forcing technique used are appropriate here, which superficially might appear to be technical detail but, in fact, reflect something fundamental about ocean-atmosphere interaction as pertinent to THC dynamics. The use of mixed thermohaline surface boundary conditions means that the atmosphere is assumed to control the exchange of freshwater with the ocean and is assumed to have an unchanging temperature structure, resultant from which is a surface heat exchange proportional to the temperature difference across the ocean-atmosphere interface [Haney, 1971]. While a mixed boundary condition formulation leaves out some feedbacks, particularly the one between atmospheric water vapor transport and the THC [Nakamura et al., 1994], it does reasonably parameterize air-sea interaction to lowest order and is, under highly simplified circumstances, rigorously derivable from a coupled model [Marotzke, 1996]. The numerical value of the air-sea thermal coupling coefficient in the Newtonian damping law reflects implicit assumptions about atmospheric heat transports [Rahmstorf and Willebrand, 1995; Marotzke, 1996] and is crucial for the stability of the THC [Zhang et al., 1993; Mikolajewicz and Maier-Reimer, 1994; Rahmstorf and Willebrand, 1995]. We expect this coefficient to play an important quantitative role in these simulations. However, we do not expect the choice of coefficient to have any qualitative consequences. Largely, this expectation arises from previous experience that has shown that the THC behavior differs quantitatively, but not qualitatively, between coupled and uncoupled models [e.g., Bryan, 1986; Manabe and Stouffer, 1988; Marotzke and Willebrand, 1991; Marotzke, 1996].

While fully coupled ocean-atmosphere simulations are desirable, robust paleoclimate model studies require that numerous sensitivity tests be performed, an issue we will address here with regard to the vertical mixing and continental runoff parameterizations. These tests are essential in order to produce a spectrum of plausible solutions within the limitations of the model parameterizations (e.g., diapycnal diffusivity), uncertainty in initial conditions, and uncertainty in climatic boundary conditions (e.g., continental runoff, evaporation and precipitation patterns, and paleobathymetric reconstructions, to name a few). The utility of existing fully coupled models in a study such as this is therefore severely limited by their speed.

\section{Results}

\subsection{Control Case and the Response to E-P Perturbations}

In all runs, temperature and wind stress forcing are identical. The ocean model was run first with the $E-P$ forcing predicted by the AGCM and corrected to account for continental runoff as described in section 2 (experiment 1 ). The standard case $(1 \times E-P)$ was run for 3000 years, by which time it had nearly reached

Table 1. Mean Ocean Temperature and Thermocline Temperature and Salinity ${ }^{2}$.

\begin{tabular}{ccccc}
\hline & & & \multicolumn{2}{c}{ Thermocline $(-600 \mathrm{~m})$} \\
\cline { 4 - 5 } Experiment & $E$ - $P$ Factor & Mean Ocean $T,{ }^{\circ} \mathrm{C}$ & $T,{ }^{\circ} \mathrm{C}$ & $S$, psu \\
\hline 1 & 0.5 & 16.4 & 18.7 & 34.98 \\
& 1 & 17.0 & 19.4 & 35.02 \\
2 & 1.5 & 17.5 & 20.5 & 35.14 \\
3 & 2 & 17.9 & 21.4 & 35.25 \\
4 & 3 & 18.2 & 22.1 & 35.45 \\
5 & 4 & 18.3 & 22.7 & 35.66 \\
& 5 & DNE & DNE & DNE \\
& zonal runoff & 18.1 & 20.9 & 35.10 \\
\hline
\end{tabular}

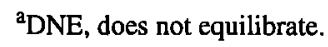




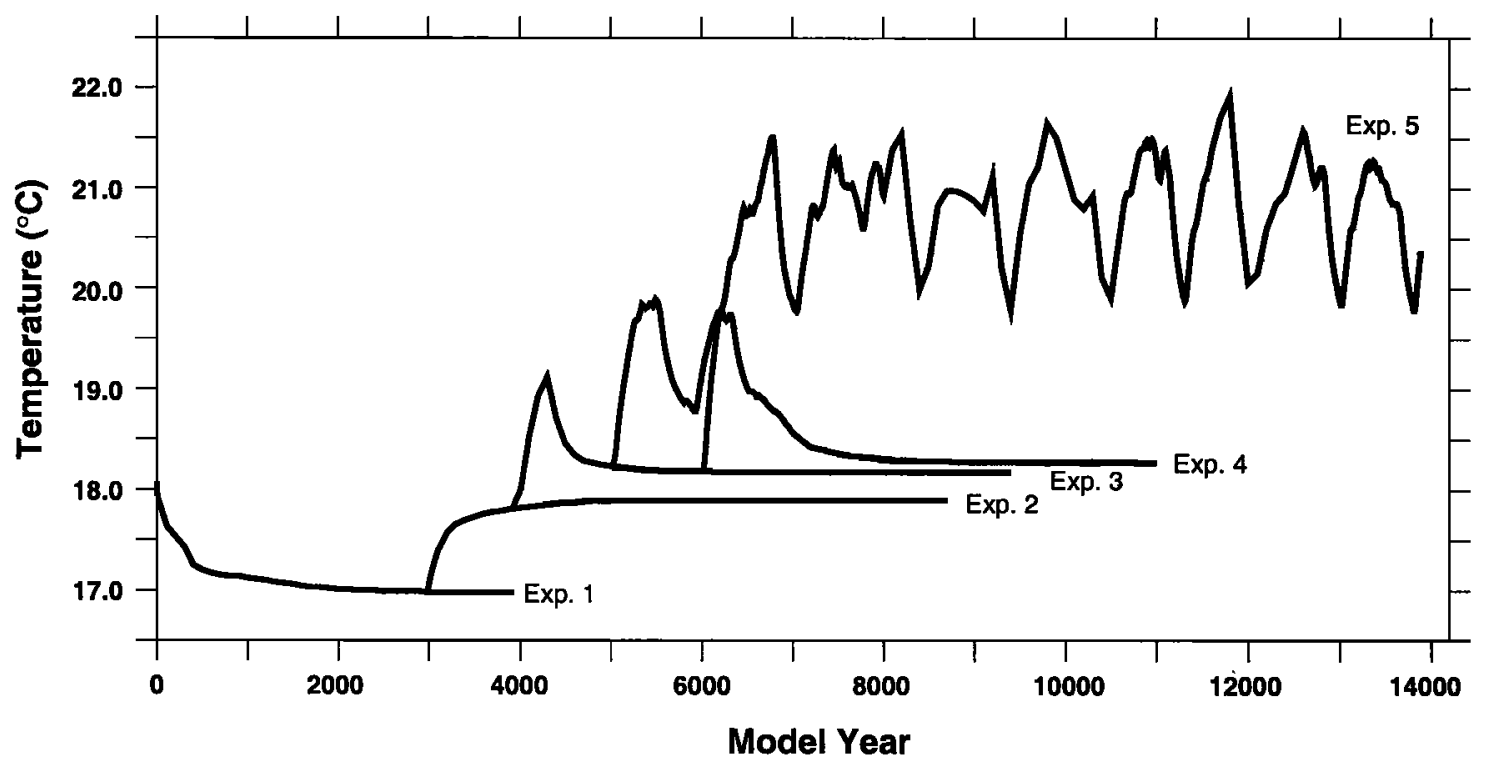

Figure 4. Time series of global ocean temperatures for experiments 1-5.

steady state. Then, in order to test the sensitivity of the model solution to the strength of the surface freshwater forcing, $E-P$ was multiplied, uniformly, by factors of from 2 to 5 (Table 1). These multiplicative factors increase the amplitude of the zonal $E-P$ forcing while keeping its spatial structure constant. The increase in multiplicative factor represents a linear increase in the subtropical-tropical moisture flux gradient and simulates an increase in the strength of the atmospheric hydrologic cycle. (Additional experiments were performed using factors of 0.5 and $1.5 \times E-P$. These data are not shown on Figure 4, but are included in Figure 6 and in Tables 1 and 2.) Figure 4 illustrates both the model integration procedure and an important response to the progressive change in E-P.

The equilibrium state of the standard run has a Northern Hemisphere intermediate water formation rate of $17 \mathrm{~Sv}$ at $44^{\circ} \mathrm{N}$, and global deep water is formed in the Southern Hemisphere at a rate of $65 \mathrm{~Sv}$ (Figure 5). Despite the very warm subpolar temperatures, the maximum surface densities occur in the high latitudes, and global intermediate and bottom waters are formed there, in agreement with previous early Eocene ocean simulations [Bice et al., 1998, 2000]. In the Northern Hemisphere, significant convection (to $\sim 1800 \mathrm{~m}$ ) is restricted to the North Pacific, near the Alaskan margin. This water is carried southwestward by a north Pacific boundary current. Intermediate depth convection (to $\sim 1500 \mathrm{~m}$ ) also occurs in the Weddell Sea region, and this water flows northward into the Atlantic basins. True deep convection occurs in the Southern Hemisphere along the Antarctic margin between Campbell Plateau and the Antarctic Peninsula. This bottom water is carried west and northward along the Campbell Plateau and New Zealand margin to fill the Pacific deep basin. It flows westward along the New Guinea margin into the Indian Ocean and is turned southward around Ninetyeast Ridge and Kerguelen Plateau. This water is prevented by topography from flowing directly into the Atlantic basins; however, above ridges south of Africa this water mixes with intermediate water formed in the Weddell Sea.

Subtropical convection occurs only in small sites and only to

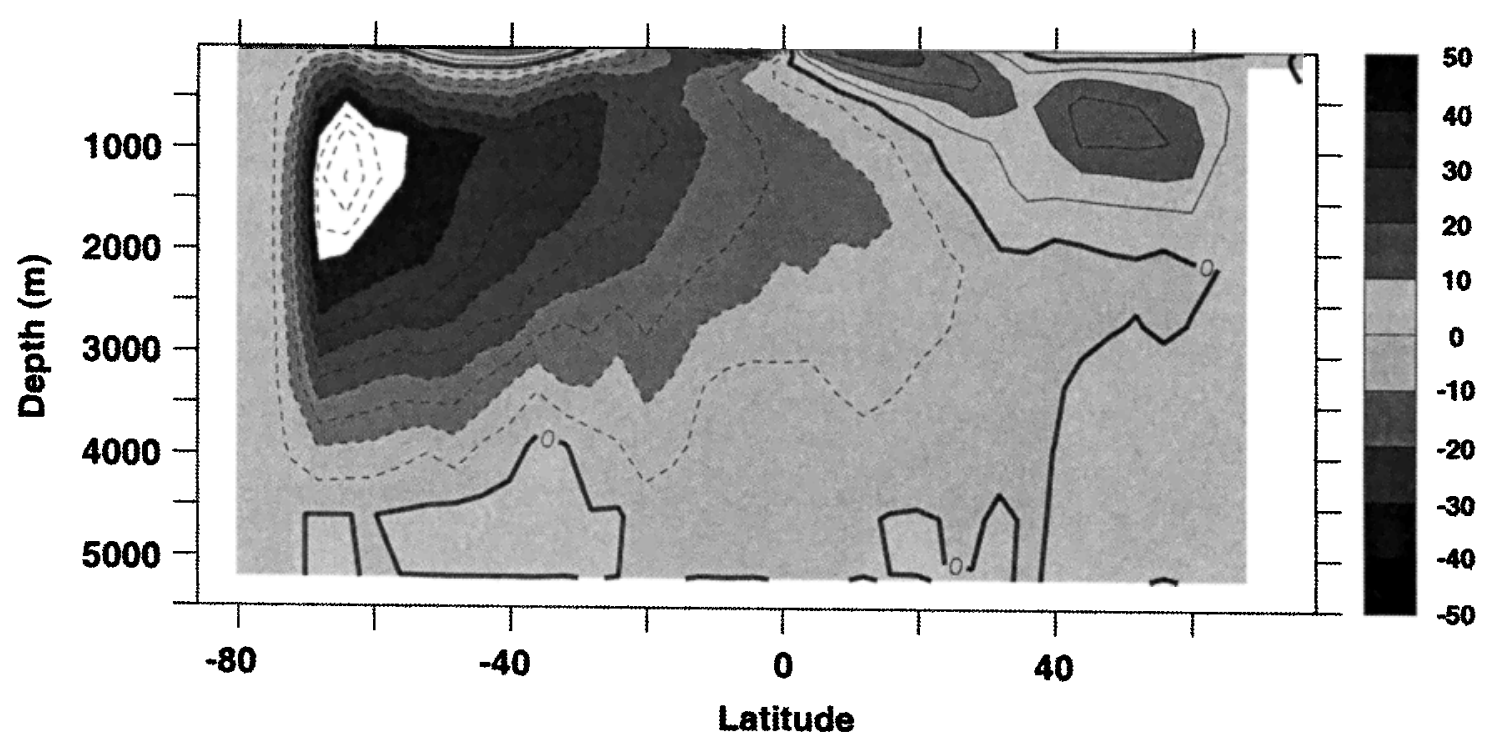

Figure 5. Global overturning stream function (sverdrups) for experiment 1. 


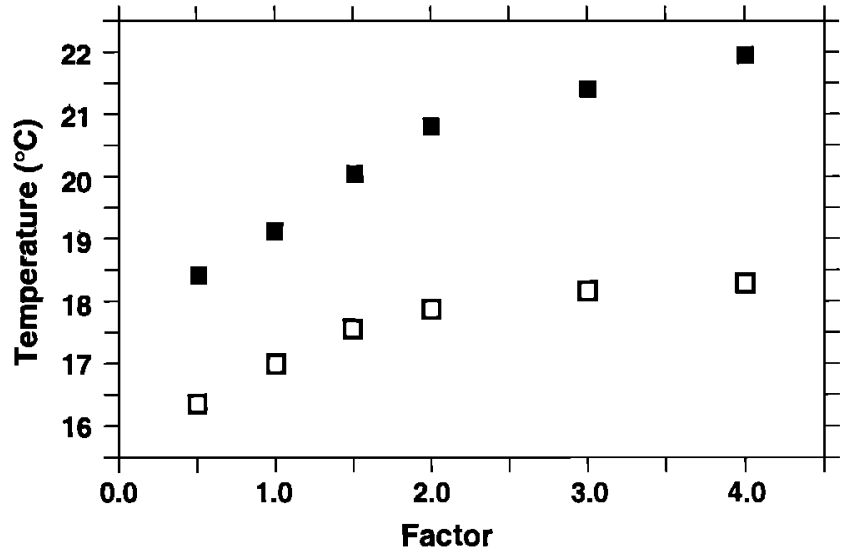

Figure 6. Global ocean temperature (open symbols) and 400$1200 \mathrm{~m}$ average temperature (solid symbols) as a function of the multiplicative factor on $E-P$.

very shallow depths, except in the Tethys. Minor convective mixing occurs in the subtropics of the western Atlantic and Pacific basins in the regions of the western boundary currents, in the western Indian Ocean over the Madagascar topographic high, and in three small regions in the subtropical South Atlantic. These convective sites do not produce discrete water masses. In the subtropical Tethys basin, convective mixing occurs in one grid cell on the western basin margin. This mixing ventilates the basin, which has a maximum depth of $1900 \mathrm{~m}$. Bottom waters in the Tethys therefore derive their properties from near $38^{\circ} \mathrm{N}$ and are warm $\left(\sim 25^{\circ} \mathrm{C}\right)$ and saline (35-35.5 psu). The densest water over the 200 m-deep sills would be neutrally buoyant at a depth of $300 \mathrm{~m}$ outside the silled basin. This localized, weak subtropical convection is similar to that observed by Bice et al. [1997] in a higher-resolution Eocene model with a full seasonal cycle and longitudinal variability in the ocean forcing. Globally, experiment 1 ocean temperatures decrease from a mean of $27.4^{\circ} \mathrm{C}$ in the uppermost layer to $14.5^{\circ} \mathrm{C}$ below $2500 \mathrm{~m}$. This bottom temperature value is a qualitatively good match to temperatures estimated from late Paleocene/early Eocene benthic foraminiferal oxygen isotopes.

In experiments $2-5$, as the multiplicative factor on $E-P$ increases, the mean ocean temperature increases (Figure 4). Warming is most pronounced in the thermocline and upper intermediate depths, between 400 and $1200 \mathrm{~m}$, and salinity also increases at these depths (the global mean salinity is unchanged). In the surface ocean the nature of the forcing change is to move salt from the extrasubtropics to the subtropics. As the $E$ - $P$ forcing increases, surface salinity increases at the latitudes of maximum Ekman pumping (subtropical downwelling). This response alone explains some of the subsurface salinity increase: Water injected into intermediate depths following an isopycnal surface is more saline.

The mechanism for the warming observed is less straightforward because the surface temperature forcing is unchanged. The increase in salinity in the subtropics causes deepening of isopycnals and any particular density surface then conveys water to a deeper depth. Ventilation of the thermocline through subduction [Luyten et al., 1983; Pedlosky, 1984] thereby carries warm, salty water to greater depths, resulting in the observed warming and contributing to the observed salinity increase. On average, 1sopycnals surfaces deepen by $50-80 \mathrm{~m}$ between experiment 1 and experiment 2 . Because this subducted water contributes to intermediate water that is transported poleward below the mixed layer, the change in water properties resulting from the increase in $E-P$ is not restricted to the subtropical thermocline. It is important to note that despite the very large subtropical evaporation and very high precipitation at high latitudes, subtropical convective mixing does not increase, and in no experiment does subtropical deep sinking (WSBW, or a "haline" mode) occur.

The global mean steady state temperature increases logarithmically with the increase in multiplicative factor on $E-P$ (Figure 6). The temperatures resulting from factors of 0.5 and $1.5 \times E-P$ forcing fit this response pattern as well. In the thermocline the salinity increase is linear in direct response to the linear change in $E-P$. Flattening of the temperature response to the increasing $E-P$ gradient (Figure 6) occurs because salinity-driven displacement of the outcropping latitude of subtropical isopycnals eventually reaches the limits of the region of Ekman pumping. Any further increase in salinity cannot produce increased thermocline ventilation. At a multiplicative factor $>4$, therefore, the subduction response becomes saturated in the experiments.

It should be noted that the subtropical gyre mean salinity increase that initiates increased subduction of warm, saline water is relatively small. As subtropical evaporation increases by a factor of 4 , the maximum grid point subtropical salinity increases by several psu, but the area-averaged subtropical salinity increases by $<0.7$ psu over the experiment 1 value (Table 2 and Figure 7). This dampened response of the mean surface salinity to large, wide-

Table 2. Subtropical Surface Salinity Maxima and Zonal Means (Upper $100 \mathrm{~m})^{\mathrm{a}}$.

\begin{tabular}{|c|c|c|c|c|c|c|c|}
\hline \multirow[b]{2}{*}{ Experiment } & \multirow[b]{2}{*}{$E-P$ Factor } & \multicolumn{2}{|c|}{$\begin{array}{c}\text { Maximum } \\
\text { Subtropical } E-P, \mathrm{~m} \mathrm{yr}^{-1}\end{array}$} & \multicolumn{2}{|c|}{$\begin{array}{c}\text { Maximum } \\
\text { Subtropical Salınity, psu }\end{array}$} & \multicolumn{2}{|c|}{$\begin{array}{c}\text { Zonal Mean } \\
\text { Subtropical Salinity, psu }\end{array}$} \\
\hline & & SH & $\mathrm{NH}$ & $\mathrm{SH}$ & NH & SH & NH \\
\hline & 0.5 & 0.368 & 0.281 & 36.07 & 36.02 & 35.54 & 35.52 \\
\hline \multirow[t]{2}{*}{1} & 1 & 0.736 & 0.561 & 37.16 & 36.94 & 35.95 & 36.03 \\
\hline & 1.5 & 1.104 & 0.842 & 37.46 & 37.56 & 36.13 & 36.26 \\
\hline 2 & 2 & 1.472 & 1.123 & 37.56 & 38.21 & 36.15 & 36.17 \\
\hline 3 & 3 & 2.208 & 1.684 & 37.64 & 39.41 & 36.21 & 36.12 \\
\hline 4 & 4 & 2.943 & 2.246 & 37.66 & 39.73 & 36.27 & 36.19 \\
\hline \multirow[t]{2}{*}{5} & 5 & 3.680 & 2.807 & DNE & DNE & DNE & DNE \\
\hline & zonal runoff & 0.862 & 0.873 & 37.25 & 37.52 & 36.03 & 35.71 \\
\hline
\end{tabular}

${ }^{2}$ SH, Southern Hemisphere; NH, Northern Hemisphere; DNE, does not equilibrate. 


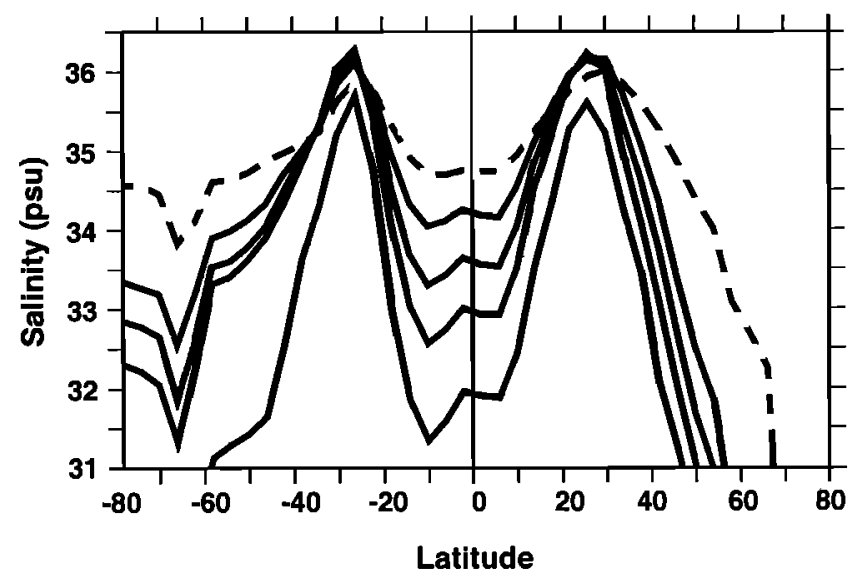

Figure 7. Zonal salinity averaged over the upper $100 \mathrm{~m}$ of the model for experiments $1-5$. The control case (experiment 1 ) is indicated by the dashed curve. Solid curves indicate the $2 \mathrm{x}, 3 \mathrm{x}, 4 \mathrm{x}$ and $5 \times E-P$ cases, with progressively decreasing tropical and highlatitude salinity. Experiment 5 (the lowest curve) is shown during one of the mixing "off" intervals of the run.

spread increases in evaporation occurs because salt is efficiently removed through deepened subduction and lower salinity water is immediately advected horizontally into the region by surface currents.

Northem Hemisphere overturning is shut off by increasing $E$ - $P$ from the standard case to $2 \times E-P$ (Figure 8 ). This occurs in response to the increase in net precipitation and decrease in surface salinity over the high-latitude North Pacific. Although the Southern Hemisphere high-latitude precipitation also increases, Southern Hemisphere meridional transport is not shut down. Salinities are maintained in the southern high latitudes by the increased poleward advection of salt through subsurface layers from the subtropics. The meridional overturning circulation established in experiment 1 therefore maintains itself by bringing salt to the high southern latitudes. However, as will be shown in the mixing events seen in experiments 3,4 and 5, this southern sinking is easily reestablished after being shut off. Boundary current trans- port of salt poleward and shallowed meridional overturning may therefore be as important as deep meridional overtuming in initiating and maintaining Southern Hemisphere deep sinking.

The Southern Hemisphere transport increase (+1 Sv) in experiment 2 is not clearly significant and does not compensate for the loss of Northern Hemisphere intermediate water production (17 Sv) seen in experiment 1 . Experiments 3 and 4 also exhibit no Northern Hemisphere intermediate water source, and the change in the strength of Southern Hemisphere overturning is not predictable, increasing to $68 \mathrm{~Sv}$ in experiment 3 , then decreasing to $52 \mathrm{~Sv}$ in experiment 4.

A strong interbasin longitudinal asymmetry is seen in the model response to changes in the zonal $E-P$ forcing. Warming and salinity increases are greatest on the westem side of the Northem Hemisphere Pacific basin (Figure 9). In experiment 2, at $-1000 \mathrm{~m}$ water depth, for example, Kuroshio Current waters warm $\sim 3^{\circ}-4^{\circ} \mathrm{C}$ relative to experiment 1 , and California Current waters cool by $\sim 1^{\circ}-1.5^{\circ} \mathrm{C}$. The asymmetric response is similar but smaller in magnitude in the North Atlantic. The South Atlantic basin warms throughout the thermocline/subthermocline region with greater warming in the poleward flowing western boundary current. Subtropical eastern South Pacific warming is $1^{\circ}-2^{\circ} \mathrm{C}$ greater than warming on the western basin margin.

The strongly asymmetric response in the Northern Hemisphere, which is most pronounced in the Pacific basin, is related to the shutdown of the intermediate depth overturning that occurred in the control case (experiment 1). The existence of this cell requires an eastern boundary density lower than the western boundary density, so that the THC is in thermal wind balance [Marotzke, 1997]. Weakening this cell requires the eastern boundary to cool, relative to the western boundary, resulting in the cold tongue in the East Pacific (Figure 9). If we consider going from experiment 2 to experiment 1 , turning on the sinking in the highlatitude eastern North Pacific takes with it the relatively warm mixed layer water and forms a classical ventilated thermocline tongue. In the southern Pacific, on the other hand, high-latitude sinking persists regardless of the $E-P$ perturbation, and so the temperature response is not as large there. Because of the narrow width of the South Atlantic basin, warm, salty water subducted to greater depths in the low latitudes is largely trapped in the Atlantic

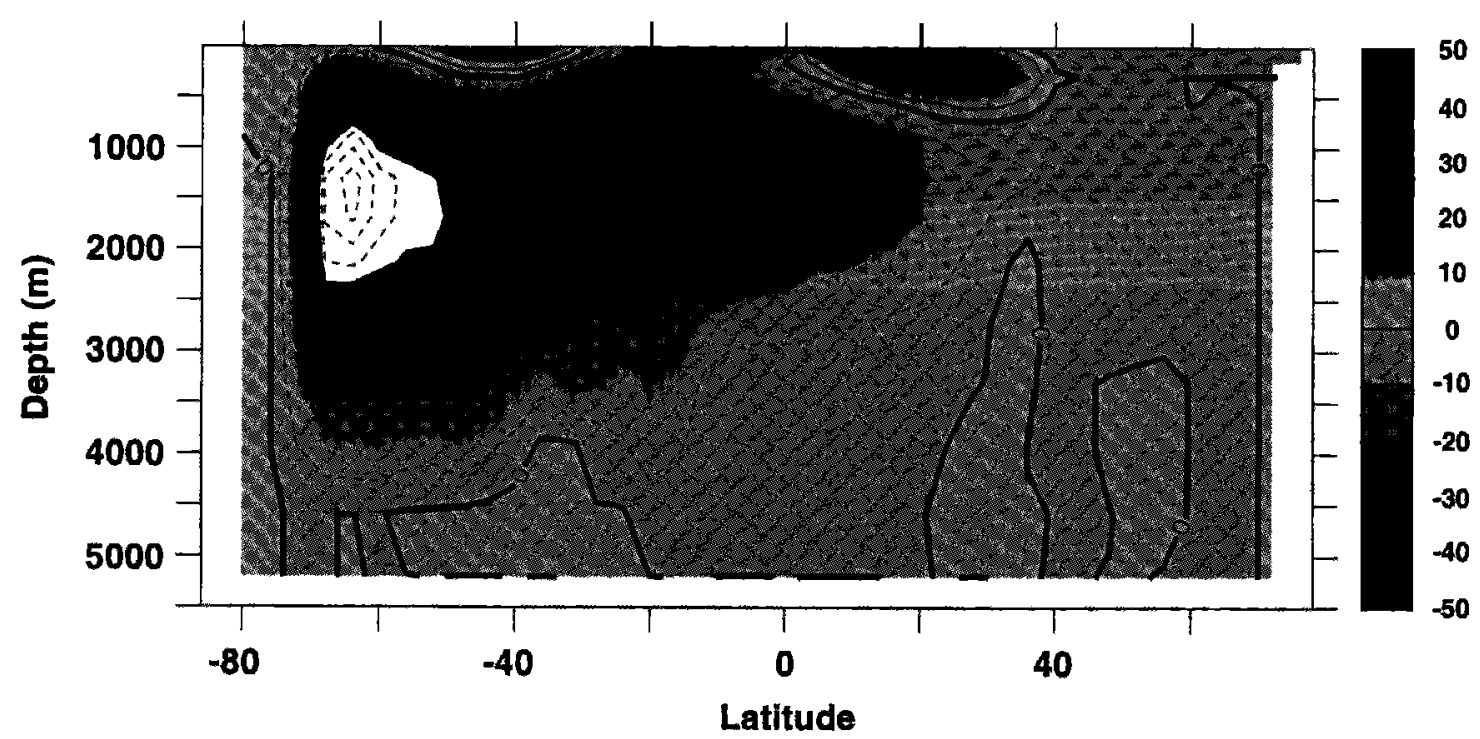

Figure 8. Global overturning stream function (sverdrups) for experiment 2. 


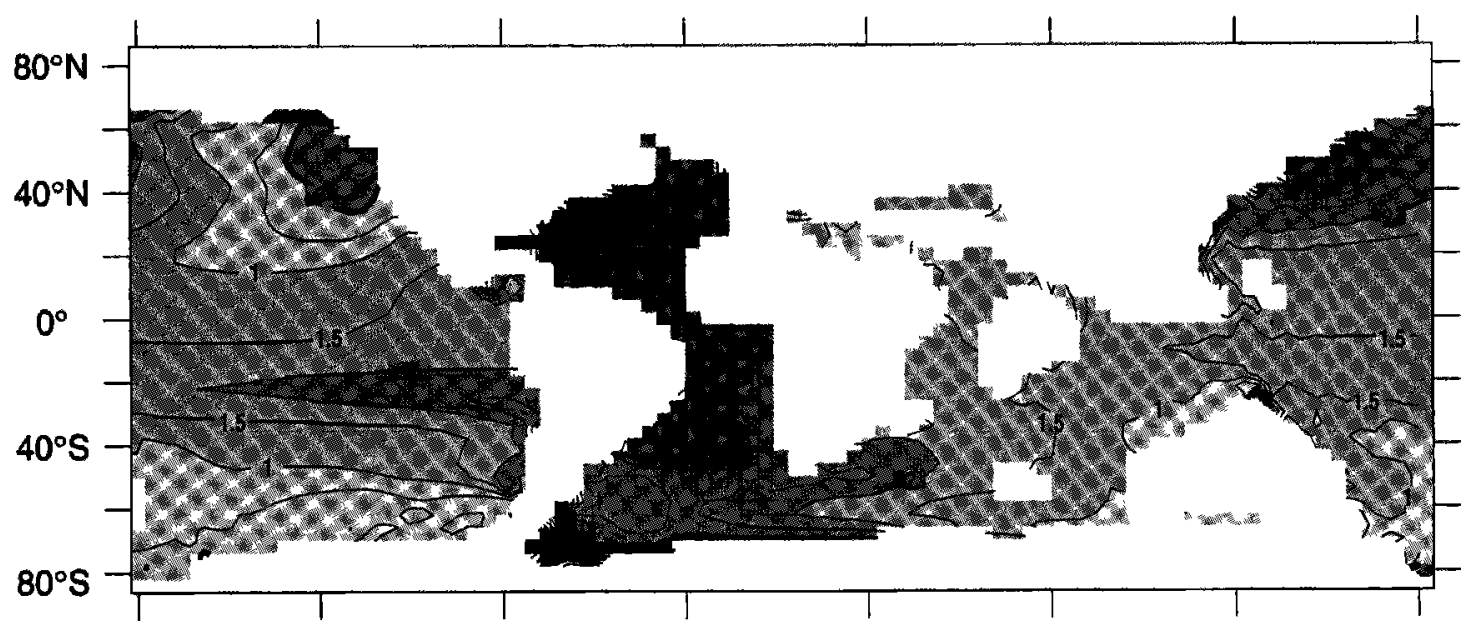

Figure 9. Temperature difference for experiment 2 minus experiment 1 , at $\sim 1000 \mathrm{~m}$ depth. The contour interval is $0.5^{\circ} \mathrm{C}$. The only region in which cooler values are predicted in the $2 \times E-P$ case is off the west coast of North America. Warming as great as $6^{\circ} \mathrm{C}$ occurs along the eastern North Atlantic margin and in the Weddell Sea.

subtropical gyre, resulting in warming on both sides of the basin This warming is strongly enhanced by the shutdown of the Weddell Sea intermediate depth convection with the change from $1 x$ to 2x $E-P$ forcing.

\subsection{Slowing of the Meridional Overturning and Transient THC Events}

In addition to the strong sensitivity of temperatures to perturbations of the moisture flux distribution, the quasi-periodic mixing events that occur also deserve close examination. These events are apparent as rapid warming/cooling cycles in Figure 4. They are most pronounced in experiment 5 (which showed no signs of equilibrating after 8000 model years) but were also observed at the beginning of experiments 3 and 4 .

Experiment 3 was initialized from year 1000 output of experiment 2, which had a Southern Hemisphere deep water formation rate of $-66 \mathrm{~Sv}$ with deep convection restricted to the Antarctic margin between Campbell Plateau and the Antarctic Peninsula. When the salinity forcing was instantaneously increased to the $3 \mathrm{x}$ $E-P$ case, deep water formation remained above $60 \mathrm{~Sv}$ for $<80$ years, and ocean temperatures increased slowly. Then, within 1 decade, meridional overturning circulation decreased to $35 \mathrm{~Sv}$, then slowed to as much as $20 \mathrm{~Sv}$ over the next several decades. During this slowing, no deep mixing occurred below $2000 \mathrm{~m}$, and warming proceeded at a faster rate at all model depths. Then, within 20 years, deep sinking was reestablished in the southern high latitudes, and the overturing rate increased to a value slightly greater than the experiment 2 steady state.

The thermohaline slowing and reinvigoration are caused by high-latitude southern Pacific salinity changes. In the primary region of deep sinking, near Campbell Plateau, surface salinities decrease rapidly with the introduction of the $3 \times E-P$ forcing, decreasing sinking and slowing the meridional overturning. At the same time, at several hundred meters depth, salinities begin to increase because of increased subduction of warm saline water in the low latitudes and poleward transport of this ventilated thermocline water to the Australian/Antarctic margin region. A density instability eventually develops, driving deep sinking and the return to strong overturning circulation. In experiments 3 and 4, one or two of these flushing events mix the Pacific sector southern ocean sufficiently to allow a persistent sinking state. In other words, in the Southern Hemisphere Pacific, the subsurface transport of salt from the subtropics overcomes the local effects of the low salinity cap caused by very low $E-P$ forcing. In the $5 \times E-P$ case, however, the competing effects of precipitation at high latitudes and strong poleward salt transport appear to be roughly balanced when averaged over a thousand years or more, so that mixing "off/on" events occur repeatedly. Somewhere between a factor of 4 and $5 \times E-P$ the model, configured as described in section 2, can no longer equilibrate and oscillates between an "on" and "off" condition in the meridional overturning circulation. No haline circulation mode is ever achieved.

\subsection{Thermohaline Response to Perturbation Relaxation}

In order to examine the stability of the thermohaline solutions achieved here, "relaxation" experiments were performed in which, for example, experiment 1 was repeated using experiment 2 steady state output as the initial condition. The same procedure was performed for experiments 2 and 3 (Figure 10). These relaxation experiments required that the global ocean cool and, in the case of experiment 1 forcings, that Northern Hemisphere sinking be reestablished. In each case the model achieved the same equilibrium state as the runs first forced with that particular $E-P$ case. Given the prescribed model configuration and forcing profiles, and within the perturbation conditions explored, this model appears to have one stable mode of equilibrium. This conclusion is supported by the fact that, early in our study, experiments $1-5$ were each initialized from a motionless state with vertical temperature and salinity structures taken from modern observations. These runs obtained the same steady state solutions as those described here. This same stability (also with dominant Southern Hemisphere sinking and largely asymmetric meridional overturning) was also observed in mixed boundary condition runs using the model of Semtner and Chervin [1992] and a higher-resolution version of the early Eocene paleobathymetry [Bice, 1997; Bice et al., 1997, 1998].

\subsection{Model Sensitivity to Diapycnal Diffusivity}

The strength of the meridional circulation and therefore the model climate state are highly sensitive to the diapycnal diffusivity (vertical mixing) coefficient chosen. The sensitivity of the cir- 


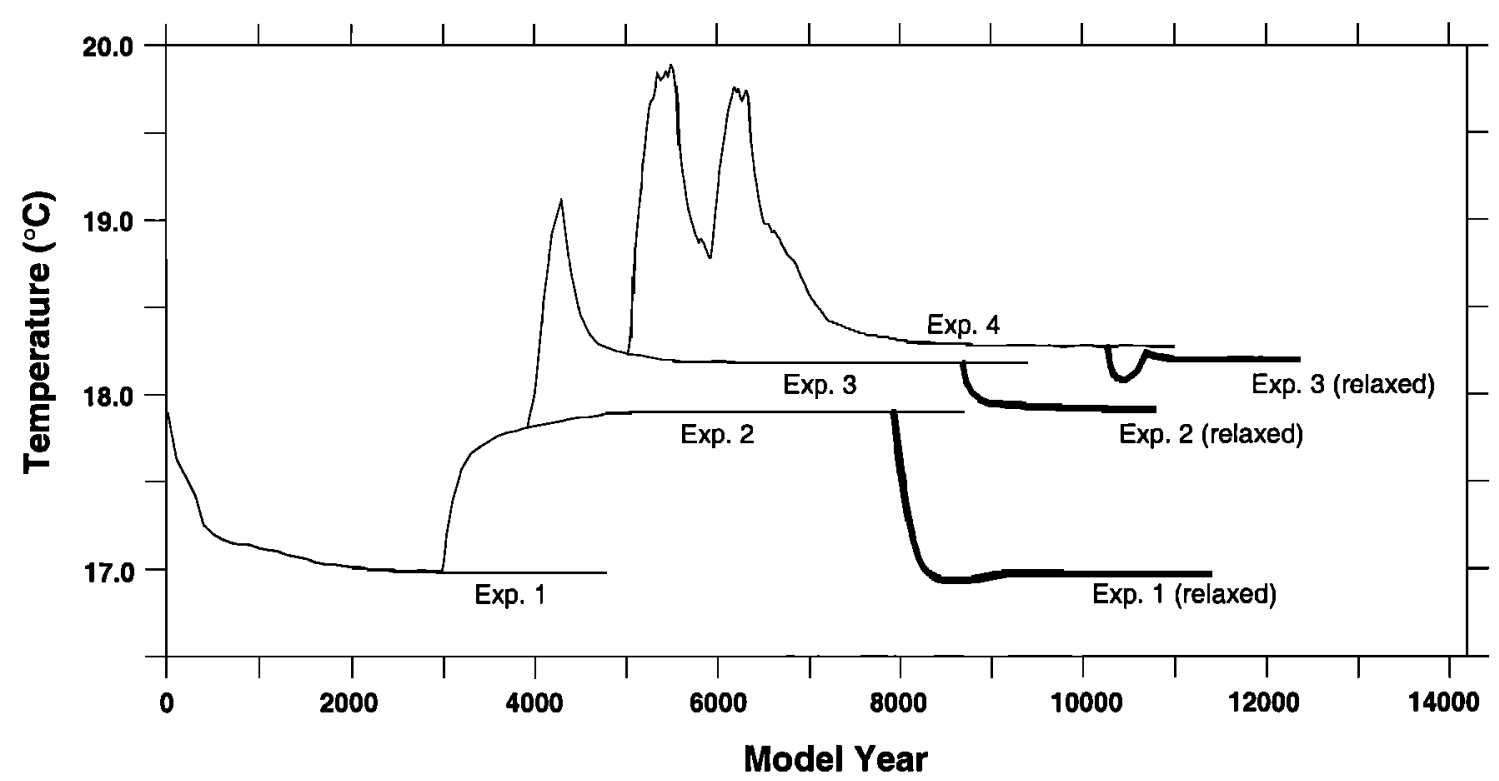

Figure 10. Time series of global ocean temperatures for experiments 1-4 and the relaxation experiments in which $1 \mathrm{x}, 2 \mathrm{x}$, and $3 \mathrm{x} E-P$ forcing runs were initialized from experiments 2,3 , and 4 , respectively.

culation to changes in the moisture flux forcing is also expected to vary with the specified vertical diffusivity [Zhang et al., 1999]. In all the experiments described above, a uniform value of $1.0 \mathrm{~cm}^{2} \mathrm{~s}^{-}$ ${ }^{1}$ was used. Although estimates of the actual values vary and spatial variability certainly exists, in the modem ocean diapycnal mixing is lowest in the upper thermocline $\left(0.1-0.15 \mathrm{~cm}^{2} \mathrm{~s}^{-1}\right.$; Ledwell et al. [1993]) and can be 1 to 2 orders of magnitude larger in the deep ocean [Toole et al., 1994; Polzin et al., 1997]. We have no way of knowing the actual mixing value for the early Cenozoic ocean. A uniform value much higher than 1.0 is not clearly defensible for Paleocene and early Eocene experiments. The highest estimates of vertical mixing rates in the modern ocean are those for the Antarctic Circumpolar region and for special topographic features such as the Brazil Basin. While rough topography and ocean floor basin structures are as likely to have existed in the early Cenozoic ocean as they are today, no Antarctic Circumpolar Current could have existed prior to the opening of the AustraliaAntarctic Passage and the Drake Passage.

In order to examine the sensitivity of the model solution to a smaller vertical mixing coefficient we repeated Experiments 1, 2, 3 , and 4, using a uniform value of $K_{v}=0.3 \mathrm{~cm}^{2} \mathrm{~s}^{-1}$. The model was integrated in a fashion similar to that described above. Time series of the mean ocean temperatures are shown in Figure 11. The smaller vertical mixing coefficient results in a control $E-P$ case that is cooler (primarily in the deep ocean) than IN experiment 1 and, as expected, has a weaker meridional overturning circulation in both the south and north. In addition, the southern overturning is shallower, with transport of $<5 \mathrm{~Sv}$ below $3000 \mathrm{~m}$. With the lower mixing coefficient the model shows a higher degree of sensitivity to perturbations of the salinity forcing. The change in tem-

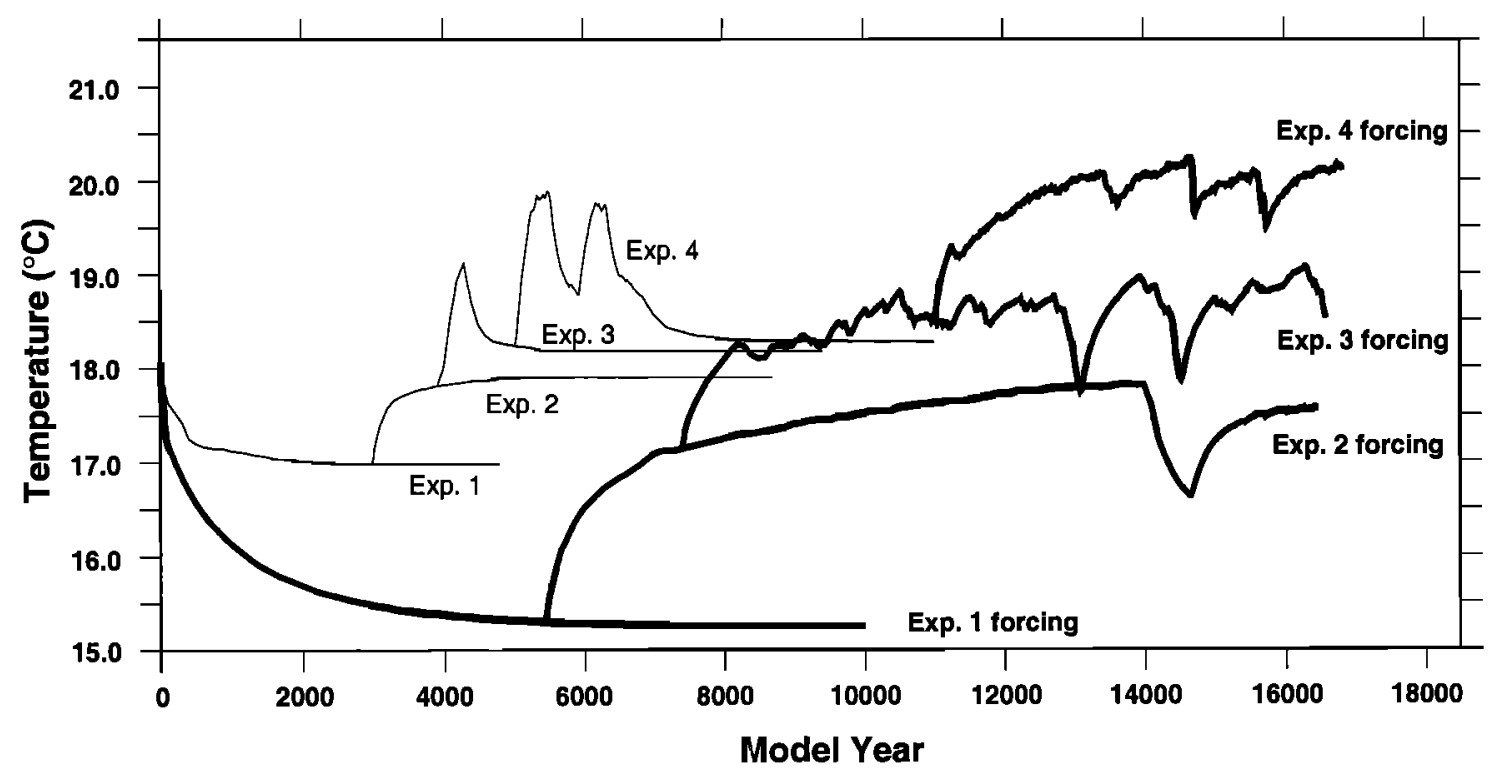

Figure 11. Time series of global ocean temperatures for experiments 1-4 (thin curves) and runs in which the same forcings were used, but with the vertical diffusivity parameter set to $0.3 \mathrm{~cm}^{2} \mathrm{~s}^{-1}$ (bold curves). 
perature between the control case $(1 \times E-P)$ and the $2 \times E-P$ case is $>+2.3^{\circ} \mathrm{C}$, nearly $1.5^{\circ} \mathrm{C}$ greater than the warming observed between experiments 1 and 2 (Table 1). A Northern Hemisphere intermediate water source is again shut down by the increase to 2 x $E-P$ forcing. Even with a factor of $4 \times E-P$ applied to the $K_{v}=0.3$ $\mathrm{cm}^{2} \mathrm{~s}^{-1}$ model, however, no reversal in thermohaline circulation occurs. Bottom water is formed in the high-latitude Southern Hemisphere, and only scattered shallow convection occurs in the subtropics, as it did in experiments described in section 3.1. At factors of 2, 3, and $4 \times E-P$ the lower $K_{v}$ model exhibits weak stability. Meridional overturning gradually slows, producing, for example, the gradual warming trend observed in the $2 \times E-P$ case. Eventually, a high-latitude density instability develops (as described for experiments 3 and 4 in section 3.1), and flushing occurs with strengthened Southern Ocean convection. The runs do not oscillate between thermohaline "on" and "off" modes or between thermohaline and haline modes of circulation. The instability is in the strength of the Southern Hemisphere meridional overturning, which varies by as much as $20 \mathrm{~Sv}$ in a decade. In all cases, renewed overturning is driven by increased high-latitude convection. The temperature dominated model solution therefore appears to be robust even with a vertical mixing value of $0.3 \mathrm{~cm}^{2}$ $\mathrm{s}^{-1}$, but the model stability is greatly reduced.

Given uncertainty in all boundary conditions (geography, temperature, moisture flux, winds) applied to a model of the early Cenozoic (or any past time period), it is very difficult to know which value of vertical mixing results in a "better" paleoceanographic simulation. Values of $1 \mathrm{~cm}^{2} \mathrm{~s}^{-1}$ and $0.3 \mathrm{~cm}^{2} \mathrm{~s}^{-1}$ may bracket a reasonable value, but we have no way of verifying this. Using such a small vertical diffusivity with uneven vertical grid spacing raises the question of spurious diffusion [Yin and Fung, 1991]. However, as later shown by Treguier et al. [1996] and discussed extensively by Marotzke [1997], the problem is less severe than was originally thought. In our experiments we see a clear influence of reducing $K_{v}$, in keeping with general expectation, but no suspicious behavior.

Another important result to note here is that the relative response of the model to changing moisture flux distribution does not change and the lower value of vertical mixing enhances the sensitivity of the model to $E-P$ perturbations. The differences between the two model solutions given identical boundary conditions but different mixing coefficients should serve as a warning that paleoclimatic studies employing ocean models can only define the range of solutions plausible within the space of the poorly constrained model parameters. In the absence of sensitivity tests such as this, no one experiment should be assumed to provide a reliable picture of past ocean conditions.

\section{Discussion}

In the control case, despite the very warm subpolar temperatures, the maximum surface densities occur in the high latitudes and global bottom water is formed there, resulting in a qualitatively good match to bottom water temperatures estimated from Paleocene/Eocene boundary interval benthic foraminiferal oxygen isotopes. This indicates that high-latitude deep water formation alone is sufficient to account for the bottom water temperatures of the early Cenozoic, as long as fossil and geochemical data support warm high latitudes. Considerable uncertainty exists in the true nature of the ancient evaporation, precipitation, and runoff distribution, but subtropical deep sinking never occurs in any $E-P$ forcing case examined here, indicating that subtropical bottom water formation is unlikely. An additional experiment was performed in which continental runoff was parameterized by a "zonal correction"; that is, net precipitation was assumed to go into the ocean at the same latitude at which it falls over the continent. In that case the zonal $E-P$ forcing resembles a factor of 1.2 to 1.5 times the experiment $1 E$ - $P$ (Table 2 ), but with much higher precipitation at high latitudes. The steady state solution with this zonal runoff correction resembles an experiment in which a 1.5 factor perturbation was applied to $E-P$, but deep convection is less widespread on the Antarctic margin, no Northern Hemisphere intermediate water source is present, and the Southern Hemisphere meridional overturning rate is weaker by $\sim 4 \mathrm{~Sv}$. The fact that a different parameterization of continental runoff has approximately the same effect as a $50 \%$ increase in the strength of the hydrologic cycle emphasizes the difficulty and importance of this poorly constrained boundary condition.

The model shows that global mean ocean temperature and thermocline through intermediate water temperatures are highly sensitive to changes in the moisture flux distribution. The response is logarithmic with the increasing $E-P$ gradient, and the strength of the response becomes saturated at very high $E-P$ forcing. Despite the weak pole-to-equator temperature gradient, vigorous meridional overturning circulation is predicted with all moisture flux forcings tried, although the absolute value of the overtuming is strongly a function of the chosen diapycnal mixing coefficient. A northern component (Pacific) intermediate source that occurs in the control case is turned off by an increase in high-latitude precipitation, but the dominating Southern Hemisphere bottom water source is not, because of subsurface transport of salt to southern high latitudes. It should therefore not be assumed that increased precipitation would have necessarily resulted in a shutdown or even a weakening of deep water formation at high latitudes in the Paleocene/Eocene ocean configuration. In the simulations described here, strong subduction and subsurface transport of warm salty water to high latitudes drives continued strong deep water production rates there.

One of our original objectives was to perform at least one model run dominated by salt forcing in order to see if a steady state solution with WSBW could be achieved. However, despite the extreme $E-P$ forcing applied and the low subtropical-to-high-

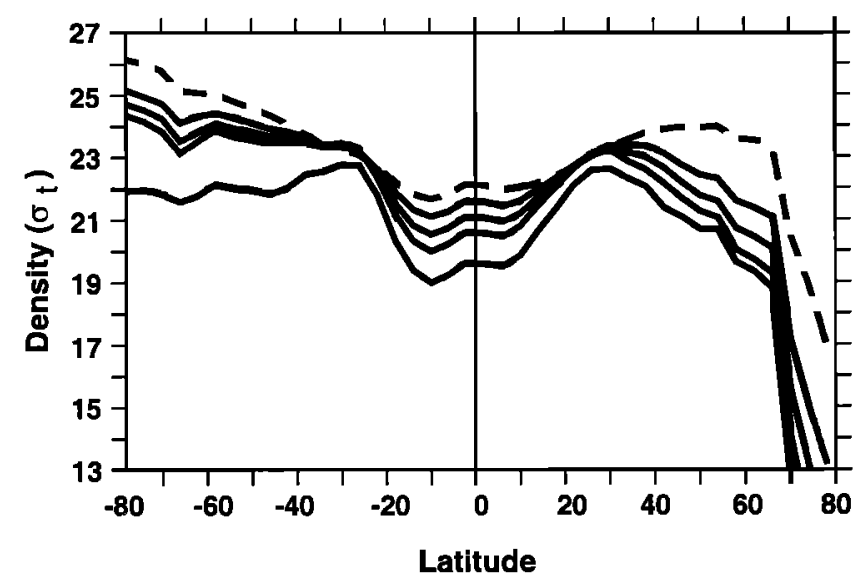

Figure 12. Zonal averaged density for the uppermost $100 \mathrm{~m}$ of the model for experiments $1-5$. The control case (experiment 1 ) is indicated by the dashed curve. Solid curves indicate the $2 x, 3 x, 4 x$ and $5 \times E-P$ cases, with progressively decreasing tropical and highlatitude surface densities. experiment 5 (the lowest curve) is shown during one of the mixing "off" intervals of the run. 
latitude surface density gradient resulting (Figure 12), subtropical deep water formation did not occur. Because of increased subduction of salt and horizontal advection of lower salinity water by currents, high salinities did not develop in the subtropics. With no dramatic widespread increase in subtropical salinities and no change in the temperature forcing, then, it was not possible to achieve a haline mode of circulation, a result consistent with Huang [1994]. Subtropical deep convection and a reversed thermohaline circulation (Stommel's second case) are therefore not supported by these experiments.

Even in the most extreme case (experiment 5), although the meridional overturning frequently collapsed, it never "turned on" with subtropical sinking, although the subtropical-to-high-latitude surface density gradient was very low. This may occur because, even during years when deep convection is not occurring, the water column is more weakly stratified in the high-latitude southern Pacific than in the subtropics of either hemisphere. In a sense, earlier strong mixing there preconditions the region, and only a relatively small density perturbation is needed to reinitiate highlatitude deep convection. It should be noted, however, that early in our study, experiment 5 forcing was applied to a motionless initial condition with a globally uniform, stable stratıfied $T-S$ structure, and the model achieved the same oscillating solution with deep convection that, when "on," occurred only in the high-latitude Southern Ocean, not in the subtropics. This suggests that poleward salt transport (enhanced by subtropical subduction) may be just as important as the existing circulation in favoring a high-latitude deep water formation mode.

Under what model conditions not explored here might subtropical deep convection and "reversed" meridional overtuming be predicted for the Paleocene/Eocene? One answer may lie in the Stommel [1961] model itself. If we make our model resemble the Stommel model by removing bottom topography and surface wind forcing, we might attain a salinity-dominated flow under some combination of temperature and salinity forcing used here. Vertical mixing even weaker than $0.3 \mathrm{~cm}^{2} \mathrm{~s}^{-1}$ might also allow a haline mode (see the discussion of Permian simulations below), but our experiments suggest that some moisture flux perturbation beyond the control value would likely still be required and that the model solution is unlikely to be stable (Figure 11). A flattened meridional temperature forcing (no gradient) might be conducive to deep convection under the regions of highest $E-P$, but a flat temperature gradient implies infinite poleward heat transport, and the resulting ocean would be isothermal. As long as any vertical temperature gradient is inferred for the ancient ocean, some meridional surface gradient must also exist. All these changes move us even further from realism than the extreme moisture flux perturbations already tested.

Our lack of a "haline mode" solution stands in contrast to recent work by Zhang et al. [2001], who achieved a haline mode (weak and unstable) with mixed boundary conditions and an idealized Permian ( $250 \mathrm{Ma})$ geography. Their study includes a subset of experiments in which temperature and wind stress were unchanged and $E-P$ (converted to a salt flux, as in our experiments) was increased by at least a factor of 5 . With a diapycnal mixing coefficient of $0.5 \mathrm{~cm}^{2} \mathrm{~s}^{-1}$ they achieved a haline mode at a factor of $5 \times E-P$. With a smaller vertical mixing value $\left(K_{\nu}=0.1\right.$ $\mathrm{cm}^{2} \mathrm{~s}^{-1}$ ) the haline mode occurred at $2 \times E-P$. As was shown by Zhang et al. [1999], the lower vertical mixing value used by Zhang et al. [2001] enhances the model response to a change in the salinity forcing. However, even with a mixing value of 0.3 $\mathrm{cm}^{2} \mathrm{~s}^{-1}$ (Figure 11), our model did not result in a reversed circula- tion, while R. Zhang and colleagues observed a haline mode with a value of $0.5 \mathrm{~cm}^{2} \mathrm{~s}^{-1}$. A significant difference between our study and that of Zhang et al. [2001] is the paleogeography used and our use of a complex or "more realistic" bathymetry for the Paleocene/Eocene. The presence of seafloor topography allows for the development of deep stratification [Vallis, 2000], a condition that makes it more unlikely that a surface salinity gradient can dominate the meridional density gradient and force a reversed (haline) meridional overturning circulation. The results of Vallis [2000] indicate that this topography need not be complex but that it be present in the region of deep water formation. Since we cannot know a priori where deep water formation occurred in the ancient ocean we wish to study, this result argues for use of a "realistic" reconstruction of topography in paleoclimate ocean modeling, as opposed to flat bottom oceans. Unfortunately, the reconstruction of seafloor topography prior to the Cretaceous is almost entirely unconstrained by data [Bice et al., 1998].

Another result with important implications for paleoclimatic studies is the surface salinity response in the ocean circulation model. The assumption is often made that highly saline subtropical surface waters would be indicative of likely paleogeographic sites of deep convection in subtropical regions, if such convection occurred. To that end, sedimentologic, isotopic, or faunal evidence of saline conditions is sometimes sought [Schmitz et al., 1996]. However, our experiments indicate that even given very high evaporative fluxes, high surface salinities can be supported only in very small regions and widespread regions of abnormally high subtropical salinities would not occur, if subtropical surface water properties are being mixed into the subsurface (in this case through subduction/thermocline ventilation) and if the basin is in communication with the global ocean, allowing throughgoing winddriven currents to mix the surface waters. Once a more restricted Tethyan basin was formed, it is more likely that widespread high salinities would develop and that a Mediterranean-Water-like "Tethyan Component" water mass of intermediate depth might have existed. It should be noted, however, that widespread evaporites (deposits of primarily gypsum, anhydrite, and halite) such as those of the lower Eocene in northern Pakistan [Meissner et al., 1974; Pivnik and Wells, 1996] would indicate that such a water mass did not exit the basin and that salt was instead removed through evaporite mineral formation.

In some respects, the short-lived changes in the meridional overturning circulation observed at the start of experiments 3 and 4 resemble the responses observed in previous studies of THC stability [Marotzke, 1989, 1990; Weaver et al., 1991, 1993; Weaver and Sarachik, 1991; Winton and Sarachik, 1993]. A "collapsed" THC state is achueved, occurs in the presence of wind forcing, is not an equilibrium solution, and subsequent flushing occurs. The deep-decoupling oscillations appear to be transient responses and do not persist unless an extreme $E-P$ forcing is applied (experiment 5). Although abrupt, short-lived thermohaline events are inferred from the paleoclimate record (e.g., the late Paleocene thermal maximum, Miller et al. [1987], Thomas [1990], Thomas and Shackleton [1996]), it is not yet clear to us whether the model thermohaline off/on oscillations represent plausible events for the real ocean. Certainly a several-fold increase in the hydrologic cycle can be considered implausible. Resolution of the question of whether transient events at lower $E-P$ perturbations are realistic will require more extensive model testing, including experiments with longitudinal variability in forcing conditions and further experimentation with the model configuration, especially mixing parameterizations. 
Acknowledgments. This material is based upon work supported by the National Science Foundation under grant ATM-9905023 to K.L.B. and under grant ATM-0000545, which supports the Partnership in Modeling Earth System History (PSU/WHOI). The MOM2 ocean model was developed under the direction of Ron Pacanowski of the Geophysical Fluid Dynamics Laboratory. The GENESIS atmospheric model was developed at the National Center for Atmospheric Research by Starley Thompson and Dave Pollard. The GENESIS model was run on the Penn State University Cray system. The authors benefited from discussions with Alistair Adcroft, Joe Pedlosky, Kurt Polzin, Ray Schmitt, Jeff Scott, and Thomas Stocker. Jeff Scott also provided advice on the configuration of MOM and the implementation of mixed boundary conditions. The manuscript benefited from comments by Eli Tziperman, Christoph Heinze, and an anonymous reviewer. Model data visualization was done using Ferret, a freely distributed software package developed by the Thermal Modeling and Analysis Project at NOAA/PMEL. This is WHOI contribution 10217.

\section{References}

Barrera, E., S. M. Savin, E. Thomas, and C. E. Jones, Evidence for thermohaline-circulation reversals controlled by sea-level change in the latest Cretaceous, Geology, 25, 715-718, 1997.

Barron, E. J., and W. H. Peterson, Mid-Cretaceous ocean circulation: Results from model sensitivity studies, Paleoceanography, 5, 319-337, 1990.

Barron, E. J., and W. H. Peterson, The Cenozoic ocean circulation based on ocean general circulation model results, Palaeogeogr. Palaeoclimatol. Palaeoecol., 83, 1-28, 1991.

Berger, W., Impact of deep-sea drilling on paleoceanography, in Deep Drilling Results in the Atlantic Ocean: Continental Margins and Paleoenvironment, Maurice Ewing Ser. vol. 3, edited by M. Talwani, W. Hay, and W. B. F. Ryan, pp. 297-314, AGU, Washington, D. C., 1979.

Bice, K. L., An investigation of early Eocene deep water warmth using uncoupled atmosphere and ocean general circulation models: Model sensitivity to geography, initial temperatures, atmospheric forcing and continental runoff, Ph.D. thesis, 363 pp., Dept. of Geosci., Pa. State Univ., 363 pp., University Park, 1997.

Bice, K. L., E. J. Barron, and W.H. Peterson, Continental runoff and early Cenozoic bottom-water sources, Geology, 25, 951-954, 1997.

Bice, K. L., E. J. Barron, and W.H. Peterson, Reconstruction of realistic early Eocene paleobathymetry and ocean GCM sensitivity to specified basin configuration, in Tectonic Boundary Conditions for Climate Reconstructions, edited by T. Crowley and K. Burke, pp. 227-247, Oxford Univ. Press, New York, 1998.

Bice, K. L., L. C. Sloan, and E. J. Barron, Comparison of early Eocene isotopic paleotemperatures and the three-dimensional OGCM temperature field: The potential for use of model-derived surface water $\delta^{18} \mathrm{O}$, in Warm Climates in Earth History, edited by B. T. Huber, K. G. MacLeod, and S. L. Wing, pp. 79-131, Cambridge Univ. Press, New York, 2000.

Brady, E. C., R. M. DeConto, and S. L. Thompson, Deep water formation and poleward ocean heat transport in the warm climate extreme of the Cretaceous (80 Ma), Geophys. Res. Lett., 25, 4205-4208, 1998.

Brass, G. W., J. R. Southam, and W. H. Peterson, Warm saline bottom water in the ancient ocean, Nature, 296, 620-623, 1982a.

Brass, G. W., E. Saltzman, J. L. Sloan II, J. R. Southam, W. W. Hay, W. T. Holser, and W. H. Peterson, Ocean circulation, plate tectonics, and climate, in Climate in Earth History, pp. 83-89, Natl. Acad. Press, Washington, D. C., 1982b.

Bryan, F., High-latitude salinity effects and interhemispheric thermohaline circulations, Nature, 323, 301-304, 1986.

Bryan, K., Accelerating the convergence to equilibrium of ocean climate models, J. Phys. Oceanogr., 14, 666-673, 1984.

Chamberlin, T. C., On a possible reversal of deep-sea circulation and its influence on geologic climates, J. Geol, 14, 363-373, 1906.

Crowley, T. J., Paleomyths I have known, in Modeling the Earth's Climate and Its Variability, edited by R. Holland, S. Joussaume, and F. David, pp. 377-430, Elsevier Sci., New York, 1999.

Curry, W. B., and G. P. Lohmann, Carbon isotopic changes in benthic foraminifera from the western South Atlantic: Reconstruction of glacial abyssal circulation patterns, Quat. Res., 18, 218-235, 1982.

Gent, P. R., and J. C. McWilliams, Isopycnal mixing in ocean circulation models, J. Phys. Oceanogr., 20, 150-155, 1990.

Gill, A. E., Atmosphere-Ocean Dynamics, 662 pp., Academic, San Diego, Calif., 1982
Haney, R.L., Surface thermal boundary condition for ocean circulation models, J. Phys. Oceanogr., 1, 241-248, 1971.

Huang, R.X., Thermohaline circulation: Energetics and variability in a single-hemisphere basin model, J. Geophys. Res., 99, 12,471-12,485, 1994.

Hughes, T.C.M., and A.J. Weaver, Multiple equilibria of an asymmetric two-basin model, J. Phys. Oceanogr., 24, 619-637, 1994.

Kaiho, K., et al., Latest Paleocene benthic foraminiferal extinction and environmental changes at Tawanui, New Zealand, Paleoceanography, II, 447-465, 1996.

Kennett, J. P., and L. D. Stott, Proteus and Proto-Oceanus: Ancestral Paleogene oceans as revealed from Antarctic stable isotopic results; ODP Leg 113, Proc. Ocean Drill. Program Sci. Results, 113, 865-880, 1990.

Kennett, J. P., and L. D. Stott, Abrupt deep-sea warming, paleoceanographic changes and benthic extinctions at the end of the Palaeocene, Nature, 353, 225-229, 1991.

Lawver, L. A., and L. M. Gahagan, Opening of Drake Passage and its impact on Cenozoic ocean circulation, in Tectonic Boundary Conditions for Climate Reconstructions, edited by T. Crowley and K. Burke, pp. 212-223, Oxford Univ. Press, New York, 1998.

Ledwell, J. R., A. J. Watson, and C. S. Law, Evidence for slow mixing across the pycnocline from an open-ocean tracer-release experiment, Nature, 364, 701-703, 1993.

Levitus, S., Climatological atlas of the world ocean, NOAA Prof. Pap. 13, U. S. Govt. Print. Off., Washington, D. C., 173 pp., 1982.

Luyten, J. R., J. Pedlosky, and H. Stommel, The ventilated thermocline, $J$. Phys. Oceanogr., 13, 292-309, 1983.

Manabe, S., and R.J. Stouffer, Two stable equilibria of a coupled oceanatmosphere model, J. Clim., 1, 841-866, 1988.

Marotzke, J., Instabilities and multiple steady states of the thermohaline circulation, in Oceanic Circulation Models: Combining Data and Dynamics, edited by D.L.T. Anderson and J. Willebrand, pp. 501-511, Dordrecht, Boston, 1989.

Marotzke, J., Instabilities and multiple equilibria of the thermohaline circulation, Ber. Inst. Meeresked, 194, 126 pp., 1990.

Marotzke, J., Influence of convective adjustment on the stability of the thermohaline circulation, J. Phys. Oceanogr., 2l, 903-907, 1991.

Marotzke, J., Analysis of thermohaline feedbacks, in Decadal Climate Variability: Dynamics and Predictability, NATO ASI Ser., Ser. I, edited by D.L.T. Anderson and J. Willebrand, Pp. 333-378, Springer-Verlag, New York, 1996.

Marotzke, J., Boundary mixing and the dynamics of three-dimensional thermohaline circulations, J. Phys. Oceanogr., 27, 1713-1728, 1997.

Marotzke, J., and J. Willebrand, Multiple equilibria of the global thermohaline circulation, J. Phys. Oceanogr., 21, 1372-1385, 1991.

Meissner, C. R., J. M. Master, M. A. Rashid, and M. Hussain, Stratigraphy of the Kohat Quadrangle, Pakistan, U.S. Geol. Surv. Prof. Pap., 716-D, 30 pp., 1974.

Mikolajewicz, U., and E. Maier-Reimer, Mixed boundary conditions in ocean general circulation models and their influence on the stability of the model's conveyor belt, J. Geophys. Res., 99, 22,633-22,644, 1994.

Miller, K. G., T. R. Janecek, M. E. Katz, and D. J. Keil, Abyssal circulation and benthic foraminiferal changes near the Paleocene/Eocene boundary. Paleoceanography. 2. 741-761. 1987.

Mountain, G. S., and K. G. Miller, Seismic and geologic evidence for early Paleogene deepwater circulation in the western North Atlantic, Paleoceanography, 7, 423-439, 1992.

Myers, P. G., and A. J. Weaver, Low-frequency internal oceanic variability under seasonal forcing, J. Geophys. Res., 97, 9541-9563, 1992.

Nakamura, M., P. H. Stone, and J. Marotzke, Destabilization of the thermohaline circulation by atmospheric eddy transports, J. Clim., 7, 1870-1882, 1994.

Oberhänsli, H., and K. J. Hsü, Paleocene-Eocene paleoceanography, in Mesozoic and Cenozoic Oceans, Geodyn. Ser., vol. 15, edited by K. J. Hsü, pp. 85-100, AGU, Washington, D. C., 1986.

Pacanowski, R., MOM 2 documentation: Users guide and reference manual version 1.0, GFDL Ocean Group Tech. Rep. 3, 329 pp., Geophy. Fluid Dyn. Lab., Princeton, N. J., 1996.

Pak, D. K., and K. G. Miller, Paleocene to Eocene benthic foraminiferal isotopes and assemblages: Implications for deepwater circulation, Paleoceanography, 7, 405-422, 1992.

Pak, D. K., and K. G. Miller, Isotopic and faunal records of deep-water transitions, Leg 145, Proc. Ocean Drill. Program Sci. Results, 145, 265 $281,1995$. 
Pedlosky, J., On the circulation of the warm water of the subtropical gyres, J. Phys. Oceanogr., 14, 1949-1954, 1984.

Pivnik, D. A., and N. A. Wells, The transition from Tethys to the Himalaya as recorded in northwest Pakistan, Geol. Soc. Am. Bull., 108, 1295-1313, 1996.

Polzin, K. L., J. M. Toole, J. R. Ledwell, and R. W. Schmitt, Spatial variability of turbulent mixing in the abyssal ocean, Science, 276, 93-96, 1997.

Prentice, M. L., and R. K. Matthews, Cenozoic ice-volume history: Development of a composite oxygen isotope record, Geology, 16, 963966, 1988.

Rahmstorf, S., A fast and complete convection scheme for ocean models, Ocean Modell., 101, 9-11, 1993.

Rahmstorf, S., and J. Willebrand, The role of temperature feedback in stabilizing the thermohaline circulation, J. Phys. Oceanogr., 25, 787 $805,1995$.

Rahmstorf, S., J. Marotzke, and J. Willebrand, Stability of the thermohaline circulation, in The Warmwatersphere of the North Atlantic Ocean edited by W. Krauss et al., pp. 129-157, Bornträger, Berlin, 1996.

Railsback, L. B., S. C. Ackerly, T. F. Anderson, and J. L. Cisne, Palaeontological isotope evidence for warm saline deep waters in Ordovician oceans, Nature, 343, 156-159, 1990.

Rea, D. K., J. C. Zachos, R. M. Owen, and P. D. Gingerich, Global change at the Paleocene-Eocene boundary: Climatic and evolutionary consequences of tectonic events, Palaeogeogr. Palaeoclimatol. Palaeoecol., 79, 117-128, 1990.

Schmitz, B., R. P. Speijer, and M.-P. Aubry, Latest Paleocene benthic extinction event on the southern Tethyan shelf (Egypt): Foraminiferal stable isotopic $\left(\delta^{13} \mathrm{C}, \delta^{18} \mathrm{O}\right)$ records, Geology, 24, 347-350, 1996.

Semtner, A. J., Jr., and R. M. Chervin, General circulation from a global eddy-resolving model, J. Geophys. Res., 97, 5493-5550, 1992.

Shackleton, N. J., The deep sea sediment record of climate variability, Prog. Oceanogr., 11, 199-218, 1982.

Stommel, H., Thermohaline convection with two stable regimes of flow, Tellus, 13, 224-230, 1961.

Stott, L. D., J. P. Kennett, N. J. Shackleton, and R. M. Corfield, The evolution of Antarctic surface waters during the Paleogene: Inferences from the stable isotopic composition of planktonic foraminifers, ODP Leg 113, Proc. Ocean Drill. Program Sci. Results, 113, 849-863, 1990.

Thomas, E., Late Cretaceous-Early Eocene mass extinctions in the deep sea, in Global Catastrophes in Earth History: An Interdisciplinary Conference on Impacts, Volcanism, and Mass Mortality (Snowbird II), edited by V. L. Sharpton and P. D. Ward, Geol. Soc. Am. Spec. Pap. 247, 481-495, 1990.

Thomas, E., and N. J. Shackleton, The Paleocene-Eocene benthic foraminiferal extinction and stable isotope anomalies, in Correlation of the Early Paleogene in Northwest Europe, edited by R. W. O'B. Knox, R. M. Corfield, and R. E. Dunay, Geol. Soc. Spec. Publ. 101, 401-441, 1996.

Thompson, S. L., and D. Pollard, Greenland and Antarctic mass balances for present and doubled $\mathrm{CO}_{2}$ from the GENESIS version 2 global climate model, J. Clim., 10, 871-900, 1997.

Toole, J. M., K. L. Polzin, and R. W. Schmitt, Estimates of diapycnal mixing in the abyssal ocean, Science, 264, 1120-1123, 1994.

Treguier, A. M., J. K. Dukowicz, and K. Bryan, Properties of nonuniform grids used in ocean general circulation models, J. Geophys. Res., 101, 20877-20881, 1996.

Vallis, G. K., Large-scale circulation and production of stratification: Effects of wind, geometry, and diffusion, J. Phys. Oceanogr., 30, 933954,2000 .

Wang, X., P. H. Stone, and J. Marotzke, Global thermohaline circulation, part I; Sensitivity to atmospheric moisture transport, J. Clim., 12, 71 82,1999 a.

Wang, X., P. H. Stone, and J. Marotzke, Global thermohaline circulation, part II; Sensitivity with interactive atmospheric transports, J. Clim., 12, 83-91, 1999b.

Weaver, A.J., and E.S. Sarachik, The role of mixed boundary conditions in numerical models of the ocean's climate, J. Phys. Oceanogr., 21, 1470-1493, 1991.

Weaver, A. J., E. S. Sarachik, and J. Marotzke, Freshwater flux forcing of decadal and interdecadal oceanic variability, Nature, 353, 836-838, 1991.

Weaver, A. J., J. Marotzke, P. F. Cummins, and E. S. Sarachik, Stability and variability of the thermohaline circulation, J. Phys. Oceanogr., 23, $39-60,1993$

Winton, M., and E.S. Sarachik, Thermohaline oscillations induced by strong steady salinity forcing of ocean general circulation models, $J$. Phys. Oceanogr., 23, 1389-1410, 1993.

Yin, F. L., and I. Y. Fung, Net diffusivity in ocean general circulation models with nonuniform grids, J. Geophys. Res., 96, 10,773-10,776, 1991.

Zachos, J. C., D. K. Rea, K. Seto, R. Nomura, and N. Niitsuma, Paleogene and Early Neogene deep water paleoceanography of the Indian Ocean as determined from benthic foraminifer stable carbon and oxygen isotope records, in Synthesis of Results of Scientific Drilling in the Indian Ocean, Geophys. Monogr. Ser., vol. 70, edited by R. A. Duncan et al., pp. 351-385, AGU, Washington, D. C., 1992.

Zachos, J. C., K. C. Lohmann, J. C. G. Walker, and S. W. Wise, Abrupt climate change and transient climates during the Paleogene: A marine perspective, J. Geol., 101, 191-213, 1993.

Zhang, J., R. W. Schmitt, and R. X. Huang, The relative influence of diapycnal mixing and hydrologic forcing on the stability of the thermohaline circulation, J. Phys. Oceanogr., 26, 1096-1108, 1999.

Zhang, R., M. J. Follows, J. P. Grotzinger, and J. Marshall, Could the Late Permian deep ocean have been anoxic?, Paleoceanography, in press, 2001

Zhang, S., R. J. Greatbatch, and C.A. Lin, A re-examination of the polar halocline catastrophe and implications for coupled ocean-atmosphere modelling, J. Phys. Oceanogr., 23, 287-299, 1993.

K. L. Bice, Department of Geology and Geophysics, Mail Stop 23, Woods Hole Oceanographic Institution, Woods Hole, MA 02543. (kbice@whoi.edu)

J. Marotzke, School of Ocean and Earth Science, Southampton Oceanography Centre, University of Southampton, European Way, Southampton SO14 3ZH, England, UK. (Jochem.Marotzke@ soc.soton.ac.uk)

(Received July 19, 2000; revised March 6, 2001; accepted March 15, 2001.) 